\title{
Status Report on Scoping Reactor Physics and Sensitivity/Uncertainty Analysis of LR-0 Reactor Molten Salt Experiments
}

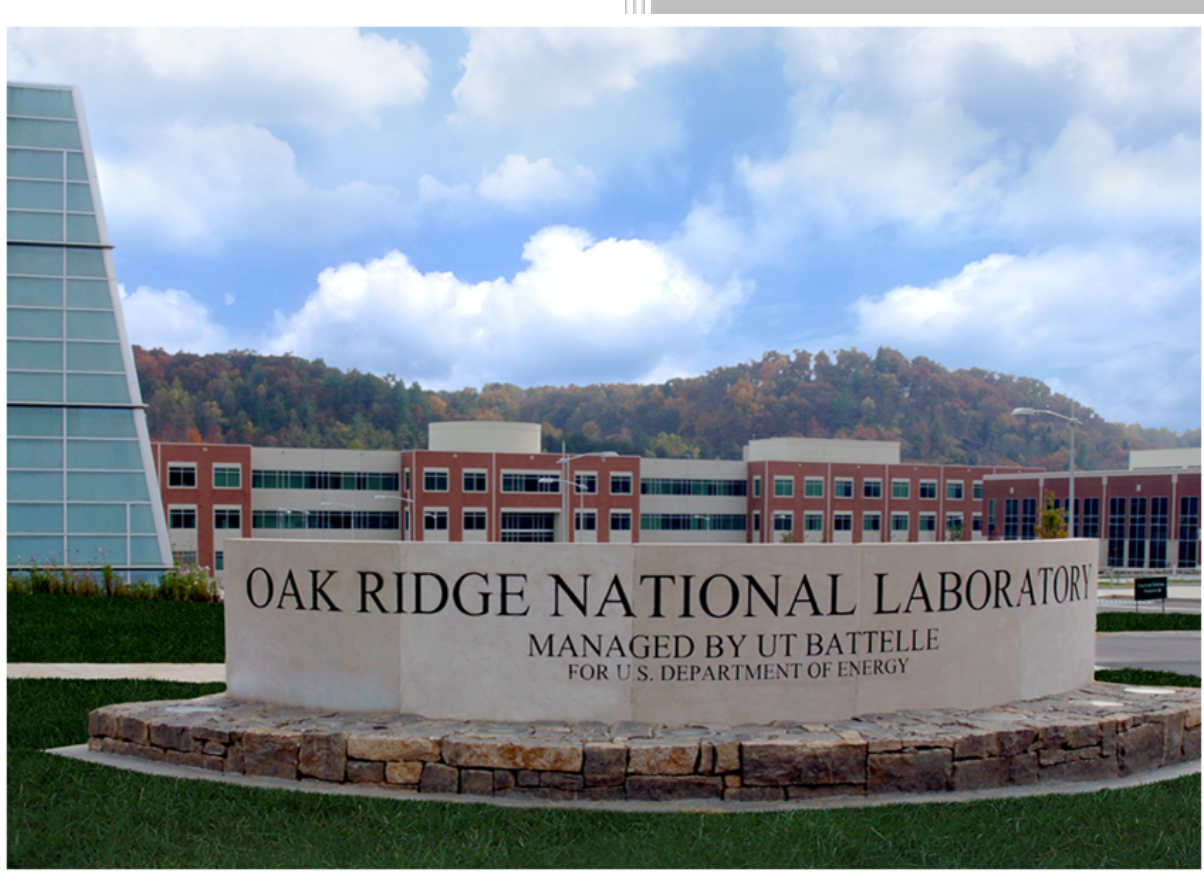

Nicholas R. Brown Donald E. Mueller Bruce W. Patton Jeffrey J. Powers

August 2016 


\section{DOCUMENT AVAILABILITY}

Reports produced after January 1, 1996, are generally available free via US Department of Energy (DOE) SciTech Connect.

Website http://www.osti.gov/scitech/

Reports produced before January 1, 1996, may be purchased by members of the public from the following source:

National Technical Information Service
5285 Port Royal Road
Springfield, VA 22161
Telephone 703-605-6000 (1-800-553-6847)
TDD 703-487-4639
Fax 703-605-6900
E-mail info@ntis.gov
Website http://www.ntis.gov/help/ordermethods.aspx

Reports are available to DOE employees, DOE contractors, Energy Technology Data Exchange representatives, and International Nuclear Information System representatives from the following source:

Office of Scientific and Technical Information

PO Box 62

Oak Ridge, TN 37831

Telephone 865-576-8401

Fax 865-576-5728

E-mail reports@osti.gov

Website http://www.osti.gov/contact.html

This report was prepared as an account of work sponsored by an agency of the United States Government. Neither the United States Government nor any agency thereof, nor any of their employees, makes any warranty, express or implied, or assumes any legal liability or responsibility for the accuracy, completeness, or usefulness of any information, apparatus, product, or process disclosed, or represents that its use would not infringe privately owned rights. Reference herein to any specific commercial product, process, or service by trade name, trademark, manufacturer, or otherwise, does not necessarily constitute or imply its endorsement, recommendation, or favoring by the United States Government or any agency thereof. The views and opinions of authors expressed herein do not necessarily state or reflect those of the United States Government or any agency thereof. 
Reactor and Nuclear Systems Division

\title{
Status Report on Scoping Reactor Physics and Sensitivity/Uncertainty Analysis of LR-0 Reactor Molten Salt Experiments
}

\author{
Nicholas R. Brown \\ Donald E. Mueller \\ Bruce W. Patton \\ Jeffrey J. Powers
}

Date Published:

August 31, 2016

Prepared by

OAK RIDGE NATIONAL LABORATORY

Oak Ridge, TN 37831-6283

managed by

UT-BATTELLE, LLC

for the

US DEPARTMENT OF ENERGY

under contract DE-AC05-00OR22725 



\section{CONTENTS}

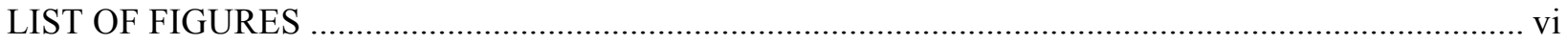

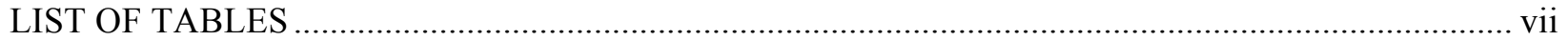

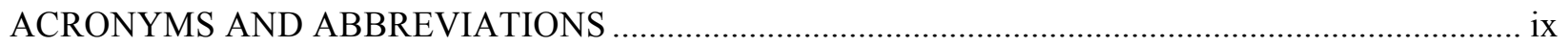

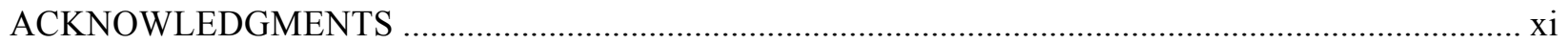

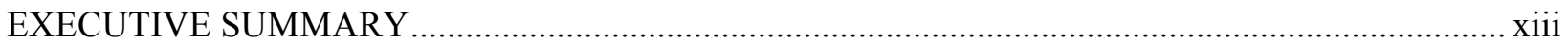

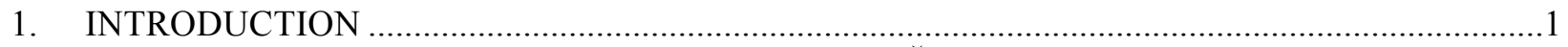

2. SUMMARY OF ORNL DELEGATION VISIT TO RC Řež ….................................................2

3. ORNL MODELLING OF LR-0 REACTOR AND SENSITIVITY/UNCERTAINTY

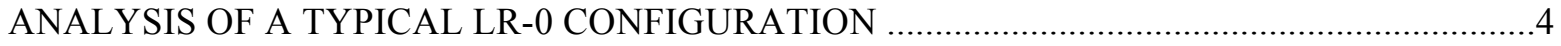

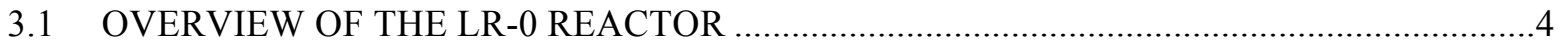

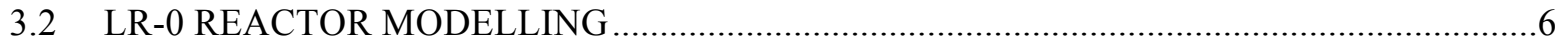

3.3 PRELIMINARY S/U ANALYSIS OF PLANNED MSRE FLIBE EXPERIMENTS ..............11

4. SENSITIVITY AND UNCERTAINTY ANALYSIS OF A TYPICAL FLUORIDE SALTCOOLED HIGH TEMPERATURE REACTOR CONFIGURATION...

5. SENSITIVITY AND UNCERTAINTY ANALYSIS OF REPRESENTATIVE LIQUID-

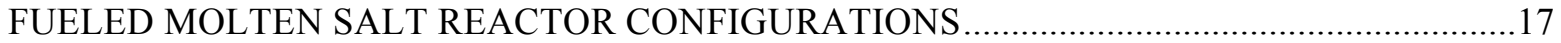

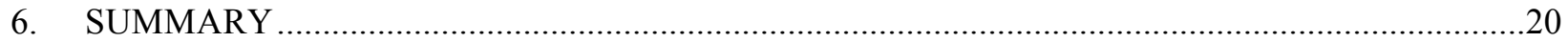

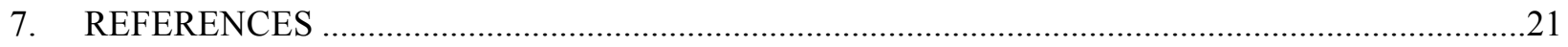




\section{LIST OF FIGURES}

Figure 1. Identification of LR-0 assembly guide tube orientation.

Figure 2. LR-0 reactor photograph during refueling with top cover removed, with five fuel assemblies in the core and the water moderator drained.

Figure 3. LR-0 reactor diagram [8].

Figure 4. KENO3D isometric projection view of the LR-0 SCALE model. ..........................................6

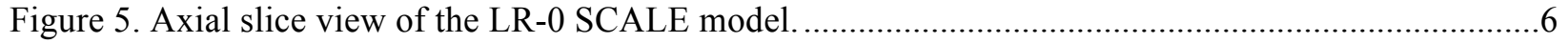

Figure 6. Planar slice view of the LR-0 SCALE model..........................................................................

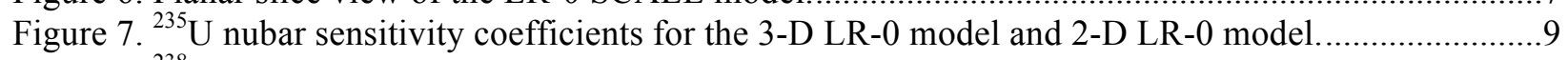

Figure $8 .{ }^{238} \mathrm{U}$ (n, gamma) sensitivity coefficients for the 3-D LR-0 model and 2-D LR-0 model. .............9

Figure 9. ${ }^{1} \mathrm{H}$ elastic scattering sensitivity coefficients for the 3-D LR-0 model and 2-D LR-0 model.

Figure $10 .{ }^{235} \mathrm{U}$ fission spectrum sensitivity coefficients for the 3-D LR-0 model and 2-D LR-0

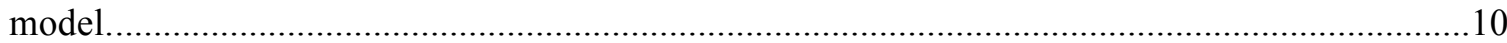

Figure 11. Planar view of the new FLiBe inserted zone for planned September 2016 experiments in the LR-0 Reactor (drawing provided by RC Řež)

Figure 12. Simplified model of the proposed FLiBe inserted zone in the LR-0....

Figure $13 .{ }^{7} \mathrm{Li}$ radiative capture sensitivity coefficients for the 3-D LR-0 model and the 2-D LR-0 model with the proposed FLiBe insertion zone. .13

Figure 14. Planar slice of the AHTR fuel assembly model used in the $\mathrm{S} / \mathrm{U}$ analysis............................14

Figure 15. ${ }^{7} \mathrm{Li}$ radiative capture sensitivity coefficients for the 3-D FHR assembly model......................15

Figure $16 .{ }^{6} \mathrm{Li}(\mathrm{n}, \mathrm{t})$ sensitivity coefficients for the 3-D FHR assembly model.......................................16

Figure 17. Unit cell geometry for an MSR application model, reproduced from Reference 15................17

Figure 18. Sensitivity coefficients for top contributors in $\mathrm{Th} /{ }^{233} \mathrm{U}$ MSR model......................................19 


\section{LIST OF TABLES}

Table 1. Effective multiplication factor for two example LR-0 configurations calculated with

KENO using the ENDF/B-VII.0 and ENDF/B-VII.1 nuclear data libraries

Table 2. Top contributors to uncertainty in effective multiplication factor from cross section covariance data for the LR-0 reactor using ENDF/B-VII.1 252-group cross sections

Table 3. Top contributors to uncertainty in effective multiplication factor from cross section covariance data for a 2-D scoping model of the LR-0 reactor . .8

Table 4. Top contributors to uncertainty in effective multiplication factor from cross section covariance data for the FHR assembly with FLiBe coolant at $99.995 \%{ }^{7} \mathrm{Li}$-enrichment. . .14

Table 5. Contribution of ${ }^{7} \mathrm{Li}$ radiative capture to overall effective multiplication factor uncertainty as a function of ${ }^{7} \mathrm{Li}$-enrichment in FLiBe coolant. .15

Table 6. Contribution of ${ }^{6} \mathrm{Li}(\mathrm{n}, \mathrm{t})$ to overall effective multiplication factor uncertainty as a function of ${ }^{7} \mathrm{Li}$-enrichment in FLiBe coolant. .16

Table 7. Top contributors to uncertainty in effective multiplication factor from cross section covariance data for the $\mathrm{Th} /{ }^{233} \mathrm{U}$ MSR unit cell with $100 \%{ }^{7} \mathrm{Li}$-enrichment in FLiBe. .18 



\section{ACRONYMS AND ABBREVIATIONS}

$\begin{array}{ll}\text { AHTR } & \text { Advanced High Temperature Reactor } \\ \text { DOE } & \text { US Department of Energy } \\ \text { FHR } & \text { fluoride salt-cooled high temperature reactor } \\ \text { FLiBe } & 2^{7} \text { LiF-BeF }_{2} \text { salt } \\ \text { FY } & \text { fiscal year } \\ \text { MSR } & \text { molten salt reactor } \\ \text { MSBR } & \text { Molten Salt Breeder Reactor } \\ \text { MSRE } & \text { Molten Salt Reactor Experiment } \\ \text { ORNL } & \text { Oak Ridge National Laboratory } \\ \text { RC Rež } & \text { Research Centre Řež } \\ \text { S/U } & \text { sensitivity and uncertainty }\end{array}$





\section{ACKNOWLEDGMENTS}

This work was supported by the US Department of Energy, Office of Nuclear Energy (DOE-NE) Advanced Reactor Technologies program. The authors would like to recognize the outstanding collaboration of Michal Kostal, Evzen Losa, Jan Uhlir, Miroslav Hrehor, Jan Milcak, and the other researchers at Research Centre Kež in the Czech Republic. Their efforts and hospitality are greatly appreciated.

The Advanced High Temperature Reactor (AHTR) model used for sensitivity/uncertainty analysis in this report is based on a model used as part of the AHTR design studies by Dan Ilas. The Molten Salt Breeder Reactor model used for sensitivity/uncertainty analysis in this report is based on a model developed in support of the Fuel Cycle Options Campaign by Jeffrey Powers, Ben Betzler, Thomas J. Harrison, and others.

The authors also thank David Holcomb, the DOE-NE Advanced Reactor Technologies Technical Area Lead for salt reactors, for his review and insights. 



\section{EXECUTIVE SUMMARY}

Experiments are being planned at Research Centre $\breve{R} e z ̌ ~(R C ~ \check{R e z ̌})$ to use the FLiBe $\left(2{ }^{7} \mathrm{LiF}_{-} \mathrm{BeF}_{2}\right)$ salt from the Molten Salt Reactor Experiment (MSRE) to perform reactor physics measurements in the LR-0 low power nuclear reactor. These experiments are intended to inform on neutron spectral effects and nuclear data uncertainties for advanced reactor systems utilizing FLiBe salt in a thermal neutron energy spectrum.

Oak Ridge National Laboratory (ORNL) is performing sensitivity/uncertainty (S/U) analysis of these planned experiments as part of the ongoing collaboration between the United States and the Czech Republic on civilian nuclear energy research and development. The objective of these analyses is to produce the sensitivity of neutron multiplication to cross section data on an energy-dependent basis for specific nuclides.

This report provides a status update on the S/U analyses of critical experiments at the LR-0 Reactor relevant to fluoride salt-cooled high temperature reactor (FHR) and liquid-fueled molten salt reactor (MSR) concepts. The S/U analyses will be used to inform design of FLiBe-based experiments using the salt from MSRE.

This status report milestone is an initial version of an expanded project report to be issued in December 2016. In FY2016, ORNL accomplished the following in support of the collaboration:

- In May 2016 a delegation from the United States visited the Czech Republic and conducted observations of experimental operations at the LR-0 reactor and also engaged in collaborative discussions on the enhancements to experiments in LR-0 that $\mathrm{S} / \mathrm{U}$ analysis can provide.

- Simplified two-dimensional and detailed three-dimensional models of the LR-0 reactor were developed using the SCALE code system. The detailed models show excellent agreement with draft benchmark evaluations intended for the International Handbook of Evaluated Reactor Physics Benchmark Experiments.

- $\quad$ Scoping S/U analyses were performed for several example configurations of the LR-0. These S/U analyses show similar sensitivities in LR-0 relative to other light water reactors, with approximately $0.61 \%$ delta- $\mathrm{k} / \mathrm{k}$ uncertainty in the neutron multiplication factor.

- Key sensitivities for a baseline configuration (without any insertions in the central experimental zone) of the LR-0 include the average number of neutrons released per ${ }^{235} \mathrm{U}$ fission and neutron scattering in ${ }^{238} \mathrm{U}$.

- Application models were adapted for S/U analysis of FHR and MSR concepts. These models are representative of the Advanced High Temperature Reactor (AHTR) and Molten Salt Breeder Reactor (MSBR) designs.

- The models were used to perform initial scoping S/U analyses for FHR and MSR concepts. An objective of the LR-0 experiments should be to generate experimental configurations that reproduce these sensitivities. Key sensitivities in FLiBe-cooled configurations include radiative capture in ${ }^{7} \mathrm{Li}$ and neutron scattering in ${ }^{7} \mathrm{Li}$. Another key sensitivity is neutron capture in ${ }^{6} \mathrm{Li}$. Parametric studies were conducted of the sensitivity of the multiplication factor to enrichment in ${ }^{7} \mathrm{Li}$. 



\section{INTRODUCTION}

There is an ongoing collaboration between the United States and the Czech Republic on civilian nuclear energy research [1,2]. Recent activity includes a joint declaration in 2010 between the US Department of Energy (DOE) and the Department of Commerce and the Ministry of Industry and Trade of the Czech Republic [1]. In addition, a Memorandum of Understanding on Cooperation in Nuclear Energy between DOE and the Czech Ministry of Industry and Trade was signed in Prague on December 12, 2012. This collaboration has included the delivery of $75 \mathrm{~kg}$ of FLiBe $\left(2{ }^{7} \mathrm{LiF}_{-} \mathrm{BeF}_{2}\right)$ fluoride salt from the Molten Salt Reactor Experiment (MSRE) at Oak Ridge National Laboratory (ORNL) to the Research Centre Řež (RC Řež) $[1,3]$. More recently, an Agreement for Cooperation in Civilian Nuclear Energy Research and Development was executed in 2014 [2].

The collaboration on MSRE salt was extended in fiscal year (FY) 2016 with a DOE Office of Nuclear Energy Advanced Reactor Technologies project. The effort is aimed at sensitivity/uncertainty (S/U) analyses of reactor physics experiments with FLiBe salt to be performed in the LR-0 low power reactor [4,5]. These experiments are intended to be a benchmarking data source to validate neutronics calculations for liquid fueled molten salt reactor (MSR) and fluoride high-temperature salt-cooled reactor (FHR) concepts [1]. MSRs are a class of advanced nuclear reactor that uses liquid fluoride or chloride salts either as a coolant with a solid fuel (as in fluoride salt-cooled high-temperature reactors) or with a fuel dissolved in liquid salt that also serves as the coolant material [12]. The $\mathrm{S} / \mathrm{U}$ analyses will be used to inform design of LR-0 experiments using US-origin FLiBe salt that was provided to the Czech Republic in 2012. The present collaboration is focused on the measurement of the reactor physics impacts of FLiBe salt enriched in ${ }^{7} \mathrm{Li}$.

The S/U evaluation will assess whether the desired neutron parameter sensitivities are achieved with the planned experiment (e.g., temperature coefficient of reactivity, neutron cross section sensitivity for specific isotopes). In addition, the $\mathrm{S} / \mathrm{U}$ analyses will be used to study previous experiments, identify potential nuclear data deficiencies with regard to FHR designs, and quantify target nuclear data improvements needed to support modeling and simulations needs. The $\mathrm{S} / \mathrm{U}$ analyses will be used to support the development of a benchmark evaluation for the proposed LR-0 critical experiments and develop a roadmap of data needs and recommendations for future experiments and collaborations.

In support of the collaboration, ORNL research staff travelled to the Czech Republic in May 2016 to develop a better understanding of the LR-0 reactor and its capabilities and to discuss past and proposed experiments with facility staff.

The ORNL effort is focused on analysis of the LR-0 FLiBe experiments using ORNL tools, including TSUNAMI-3D [6] from the SCALE code system [7], that elucidate information on continuous energy cross section $\mathrm{S} / \mathrm{U}$. This $\mathrm{S} / \mathrm{U}$ information may enable development of more impactful experiments at the LR-0 and has the potential to improve the usefulness of the reactor physics experiments conducted using the FLiBe salt.

The synergistic international effort is ongoing, and additional experiments are planned for September 2016. This milestone report is a status update as of August 2016 to document several specific technical accomplishments of the ORNL team that directly support the collaboration.

Simplified two-dimensional and detailed three-dimensional models of the LR-0 reactor were developed using the SCALE code system. The detailed three-dimensional models show excellent agreement with reference draft benchmarks intended for the International Handbook of Evaluated Reactor Physics Benchmark Experiments [8] and references in the open literature $[9,10]$. 
Scoping S/U analyses were performed for several example configurations of the LR-0. In addition, application models were adapted for S/U analysis of FHR and MSR concepts. These models are representative of the Advanced High Temperature Reactor (AHTR) [11] and Molten Salt Breeder Reactor (MSBR) [12] designs. The application models were used to perform initial scoping S/U analyses for FHR and MSR concepts. An objective of the LR-0 experiments should be to generate experimental configurations that reproduce these sensitivities.

Each of these technical outcomes directly advances the objectives of this project. One objective is to evaluate the suitability of experiments performed at the LR-0 reactor in the Czech Republic for use as MSR design and operation validation data. Another objective is to use knowledge gained from the evaluation of the LR-0 reactor experiments in the generation of recommendations for future experiments, which are expected to involve US-origin isotopically selected FLiBe salt obtained from ORNL's MSRE, thereby ensuring the desired neutron parameter sensitivities are achieved with the proposed experiments (temperature coefficient of reactivity, neutron cross section sensitivity for specific isotopes, etc.).

Additionally, it is expected that this $\mathrm{S} / \mathrm{U}$ analysis will help assess the adequacy of US nuclear data (i.e., ENDF/B) applied to MSR systems and generate recommendations for data improvements.

This status report includes a summary of the ORNL visit to Centrum vyzkumu Rez (RC Řež), development of models of LR-0 with SCALE, S/U analysis of LR-0 configurations, S/U analysis of application models, and it outlines plans for future work.

\section{SUMMARY OF ORNL DELEGATION VISIT TO RC ŘEŽ}

This section of the report provides a brief overview of ORNL staff visit to RC Řež in May 2016. Donald E. Mueller, Nicholas R. Brown, and Jeffrey J. Powers of ORNL in Oak Ridge, TN, visited the RC Řež in the Czech Republic. The visit was conducted from Tuesday, May 17, 2016, to Thursday, May 19, 2016. The visit included tours of several key facilities of RC Řež. Additionally, the visit enabled ORNL participants to observe critical experiments, develop a better understanding of the capabilities and limitations of the facility, and work with the RC Řež researchers to potentially enable development of enhanced experiment designs.

The meetings on Tuesday, May 17, 2016, included observations of several critical experiments with graphite, including the measurement of the axial profile of fission density of the driver core using gammascanning equipment. Donald Mueller and Nicholas Brown met with Jan Uhlir (Fluorine Chemistry Department), Michal Kostal (scientist at LR-0), Vlastimil Juricek (head of Rez Reactors Operation), and Jan Milcak (head of LR-0 Operations). Discussions included general opportunities for collaboration and other synergies, as well as technical discussion with Michal Kostal about gamma scanning and experimental uncertainties in LR-0. Additionally, Donald Mueller engaged in a discussion with Michal Kostal about the potential applications of $\mathrm{S} / \mathrm{U}$ analysis tools. This led to discussion about planning for future collaborations and opportunities for enhanced experiment design.

On Wednesday, May 18, 2016, Donald Mueller presented a seminar on S/U analysis and its impact on critical experiment design, and Nicholas Brown presented a seminar on the development of a point design for a fluoride high temperature salt-cooled reactor and other US advanced reactor activities. The seminar had approximately 12 attendees, including Miroslav Hrehor, director of the Safety Research Section. The seminar resulted in productive discussions on several topics covered. The ORNL participants observed additional operations at LR-0 and engaged in a consensus-building discussion about the design of a canister for future experiments using the MSRE FLiBe salt obtained by Czech Republic from the United States. There were detailed discussions with facility staff about LR-0 modeling approaches. 
In the afternoon, ORNL participants toured the RC Řež Fluorine Chemistry Laboratory and engaged in productive discussion on fluoride volatility (relevant to advanced reactor and sustainable fuel cycles), FLiBe salt, and electrochemistry.

Meetings on Thursday, May 19, 2016, included detailed discussion of modeling issues of the LR-0 reactor, including one of the main LR-0 modelers, Evzen Losa. Resolution of these issues enabled unification of preliminary ORNL models of the LR-0 reactor with the physical system, as well as the RC Řež reactor physics models. One example included identification of the physical orientation of the guide tube locations in the assemblies relevant for the past experiments related to molten salt and graphite and the planned experiments with MSRE FLiBe. This is shown in Figure 1. These in-person discussions answered questions and enabled modeling improvements for both sides of the collaboration.

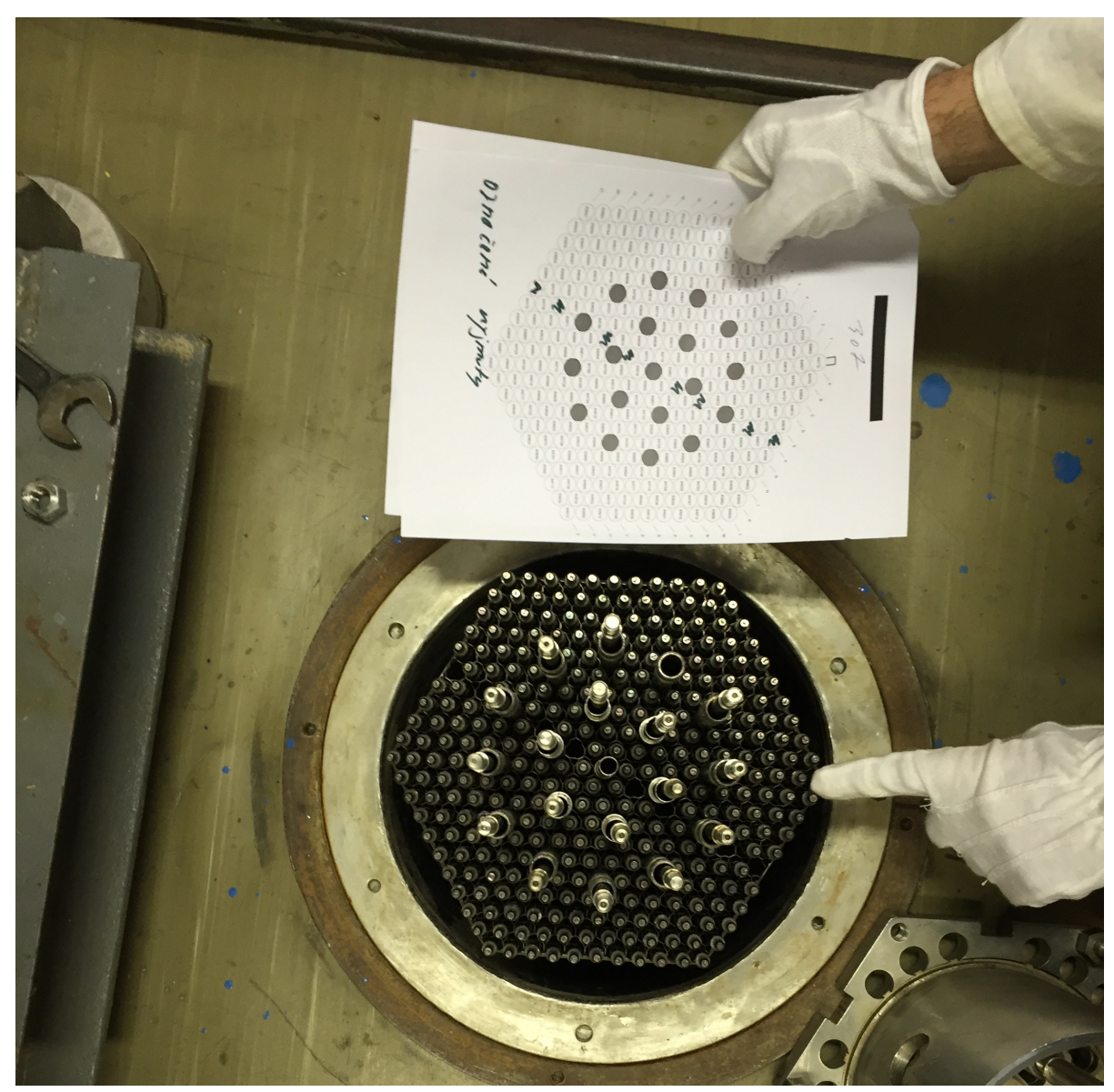

Figure 1. Identification of LR-0 assembly guide tube orientation.

The participants formulated a strategic near-term plan to collaborate on the modeling and S/U analysis of the LR-0 reactor and in particular the experiments with MSRE FLiBe salt planned for the September 2016 time frame. These plans include specific interactions throughout 2016 focused on the design, analysis, and conduct of the FLiBe experiments. 


\section{ORNL MODELLING OF LR-0 REACTOR AND SENSITIVITY/UNCERTAINTY ANALYSIS OF A TYPICAL LR-0 CONFIGURATION}

This section provides a brief overview of ORNL activities modeling the LR-0 reactor.

\subsection{OVERVIEW OF THE LR-0 REACTOR}

The LR-0 reactor is a low power reactor (critical assembly) pool type research reactor at RC Řež using partial height $\left(1 / 3^{\text {rd }}\right)$ VVER assemblies. These assemblies are radially identical, but with a reduced height relative to a VVER-1000 fuel assembly. The continuous maximal operating power is on the order of 1 $\mathrm{kW}$, and the thermal neutron flux density is $10^{9} \mathrm{n} /\left(\mathrm{cm}^{2}-\mathrm{sec}\right)$ [9]. The LR-0 reactor must have at least six fuel assemblies in a critical configuration, but it can have significantly more. For example, the VVER mini-core mockup has thirty-two $1 / 3$-height assemblies of three different uranium enrichments [5]. Reactor criticality is controlled using the height of the water moderator, and there are a variety of instrumentation tubes and possible configurations. A photograph from the top of LR-0 during refueling is shown in Figure 2, and the features of the LR-0, including a detailed diagram of the reactor, are shown in Figure 3.

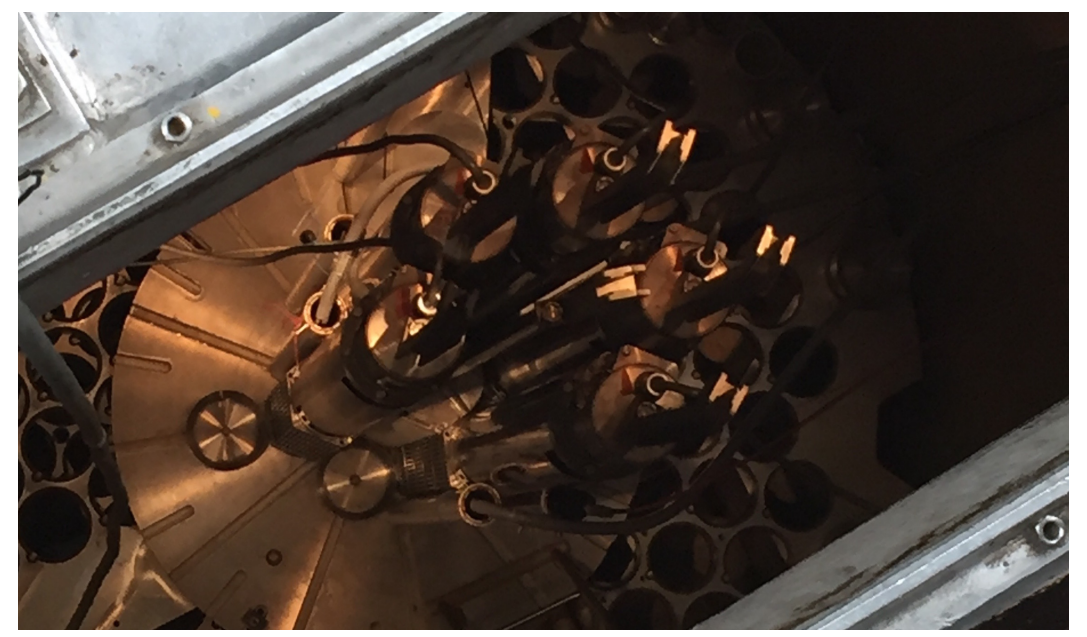

Figure 2. LR-0 reactor photograph during refueling with top cover removed, with five fuel assemblies in the core and the water moderator drained. 


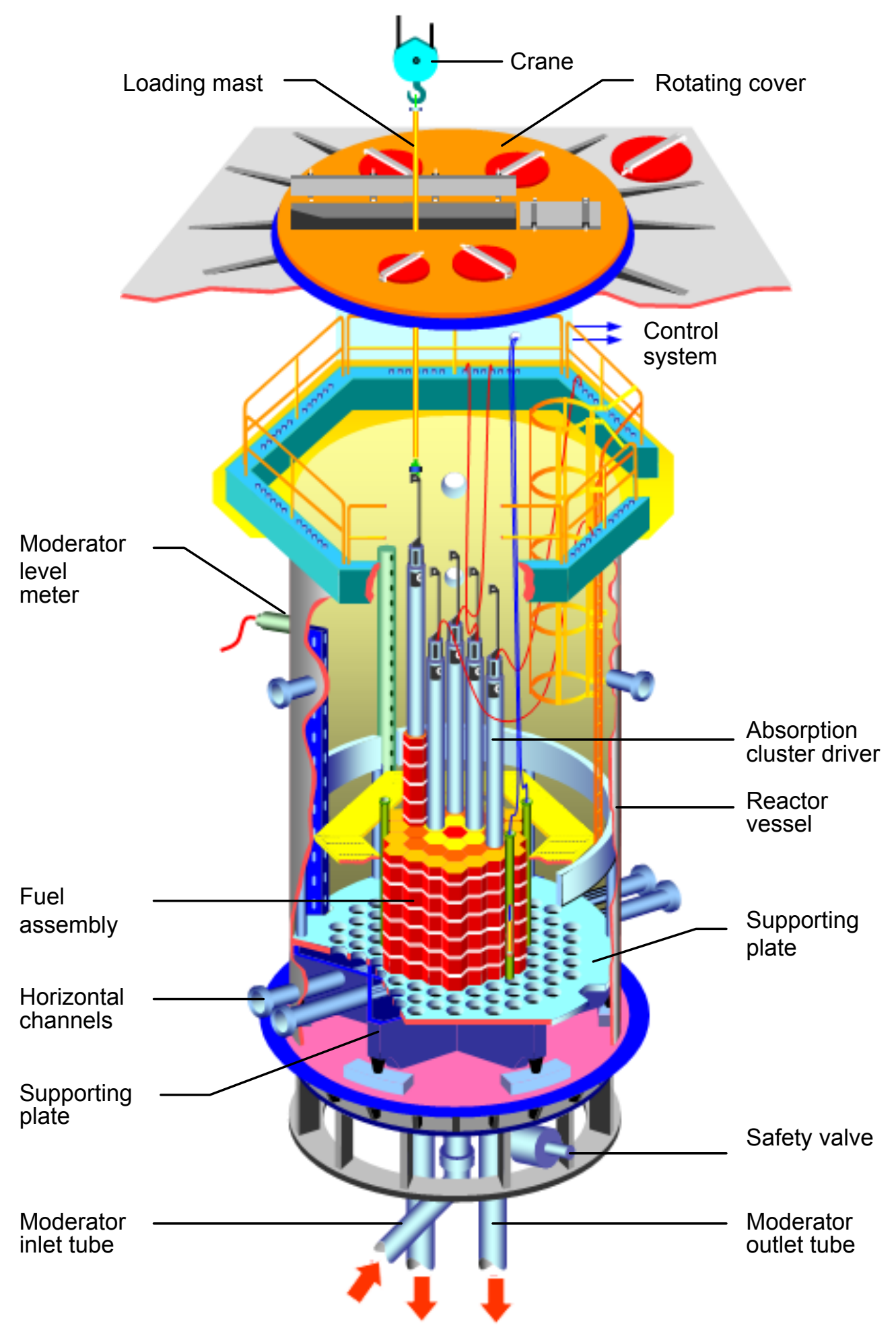

Figure 3. LR-0 reactor diagram [8]. 


\subsection{LR-0 REACTOR MODELLING}

A detailed three-dimensional SCALE [7] model of the LR-0 reactor was developed and used to analyze two example systems from Reference 10 . The key features of the LR-0 reactor were included, including the fuel assemblies, water moderator height, the lower support plate, and the un-moderated upper portion of the core. For the SCALE model, the lower plate and grid spacers were homogenized. A KENO 3-D isometric projection view of the model is shown in Figure 4.

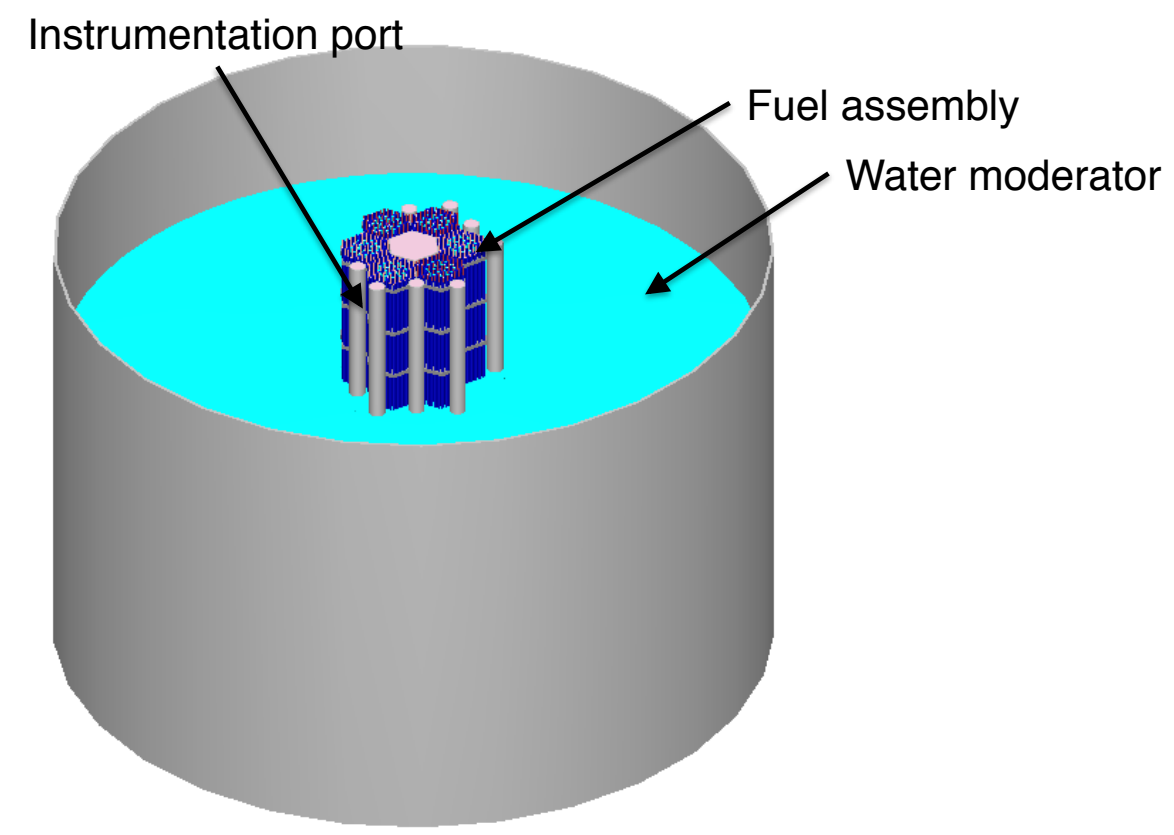

Figure 4. KENO3D isometric projection view of the LR-0 SCALE model.

An axial slice view of the model is shown in Figure 5, and a planar slice view of the fuel assemblies is shown in Figure 6.

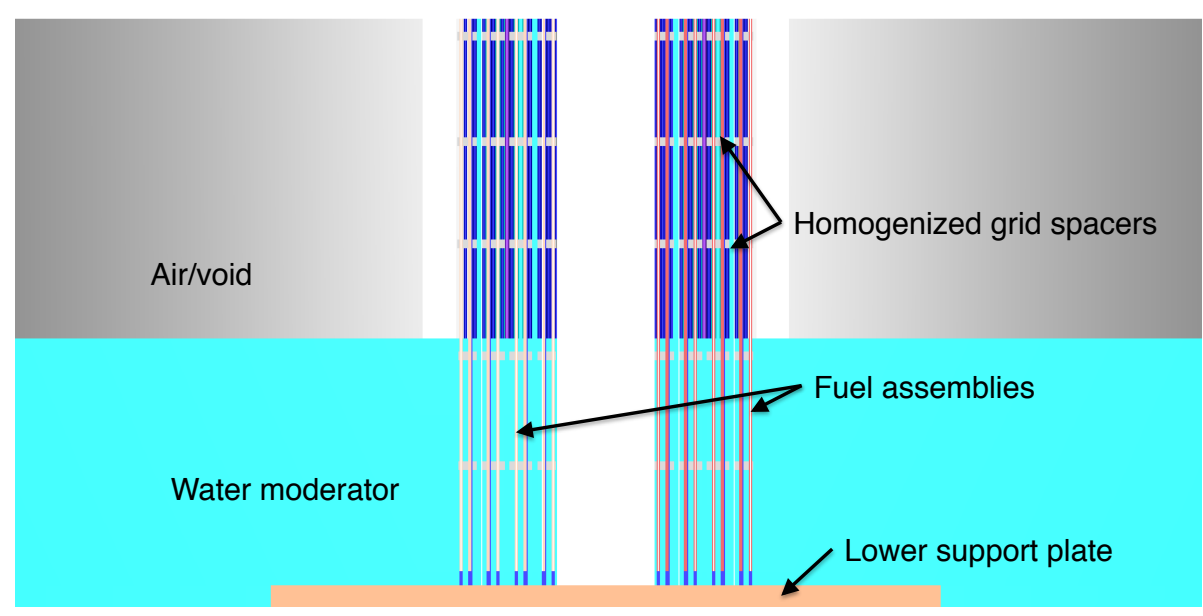

Figure 5. Axial slice view of the LR-0 SCALE model. 


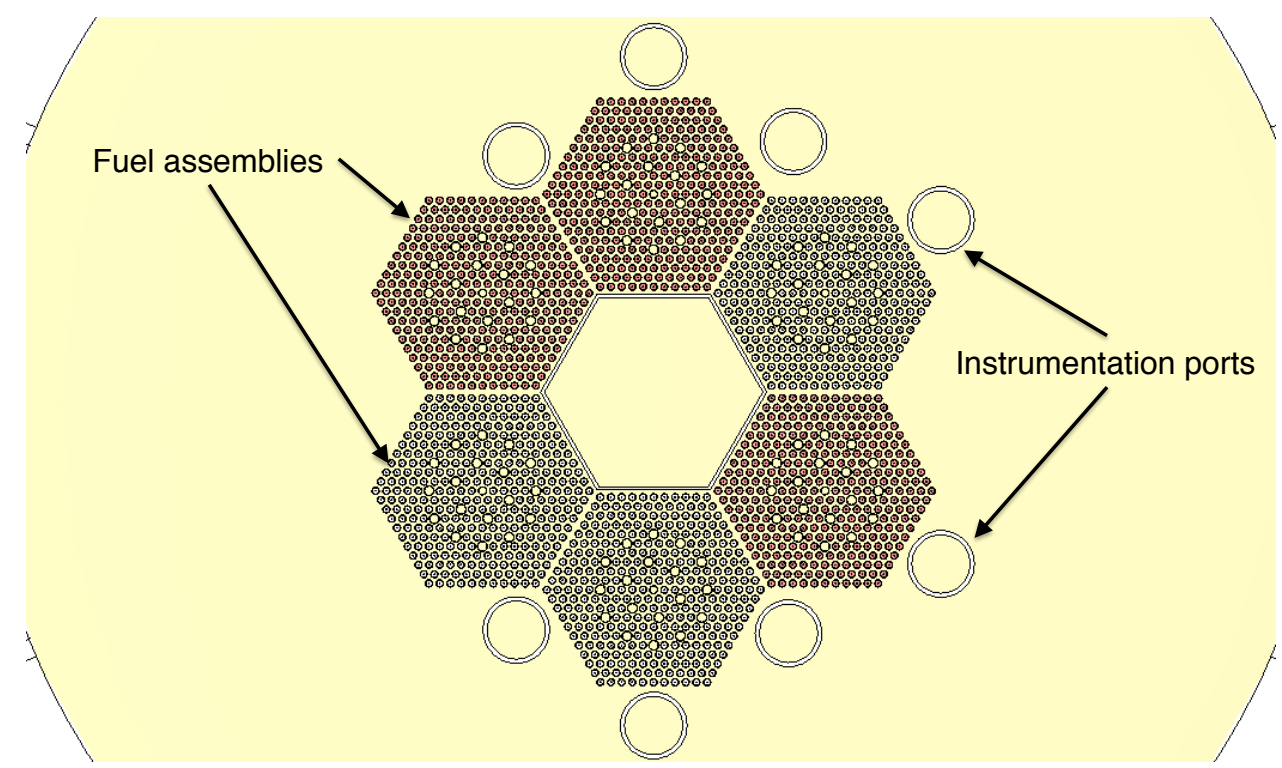

Figure 6. Planar slice view of the LR-0 SCALE model.

The model was used to generate eigenvalue and $\mathrm{S} / \mathrm{U}$ analysis results for two cases from Reference 8 and Reference 10. The first case, referred to as Case 1 in Reference 8, consists of a baseline LR-0 configuration with six fuel assemblies of approximately 3.3\% enrichment. The second case, referred to as Case 16 in Reference 8, is identical to the first case but includes an inserted zone of natural FLiBe (e.g., no enrichment in ${ }^{7} \mathrm{Li}$ ) in an Inconel container. A comparison between the measured critical moderator height in centimeters and the calculated neutron multiplication factor calculated using the KENO-VI sequence at the specified moderator height is shown in Table 1 . The calculated effective multiplication factor is very close to unity in all cases, indicating that the model of the LR-0 reactor is reasonable.

Table 1. Effective multiplication factor for two example LR-0 configurations calculated with KENO using the ENDF/B-VII.0 and ENDF/B-VII.1 nuclear data libraries

\begin{tabular}{lccc}
\hline \multicolumn{1}{c}{ Configuration } & $\begin{array}{c}\text { Measured critical } \\
\text { moderator height }(\mathbf{c m})\end{array}$ & \multicolumn{2}{c}{ Calculated $\boldsymbol{k}_{\text {eff }}$} \\
\cline { 3 - 4 } & & $\begin{array}{c}\text { ENDF/B-VII.0, } \\
\text { 238-group }\end{array}$ & $\begin{array}{c}\text { ENDF/B-VII.1, } \\
\text { 252-group }\end{array}$ \\
\hline Case 1 (base case) & 55.639 & $0.99935 \pm 0.00029$ & $0.99304 \pm 0.00028$ \\
Case 16 (Natural FLiBe) & 57.736 & $0.99748 \pm 0.00026$ & $0.99059 \pm 0.00025$ \\
\hline
\end{tabular}

Using the TSUNAMI-3D sequence, the key sensitivities for effective neutron multiplication factor in the LR-0 reactor were identified. These key sensitivities are similar to other light water reactors [6] and are shown in Table 2. Negative uncertainties in eigenvalue are due to anti-correlated covariance data, i.e. are due to shared uncertainty for two closely related quantities.

To simplify the scoping sensitivity calculations of FLiBe experiments in LR-0, a two-dimensional core model of the LR-0 reactor was created. The two-dimensional model is axially infinite and represents a radial slice of the LR-0 reactor at an axial position without grid spacers. This model is not a perfect representation of the LR-0 reactor, but the model captures some of the key eigenvalue sensitivities of LR- 0 , both overall and also as a function of energy. Therefore, the two-dimensional model is useful as a scoping tool, shown in Table 3. 
Table 2. Top contributors to uncertainty in effective multiplication factor from cross section covariance data for the LR-0 reactor using ENDF/B-VII.1 252-group cross sections

\begin{tabular}{ccccc}
\hline Nuclide & Reaction & Covariance w/nuclide & Reaction & $\begin{array}{c}\text { Uncertainty in } \boldsymbol{k}_{\text {eff }} \\
\text { (\%delta-k/k) }\end{array}$ \\
\hline${ }^{T}$ otal & N/A & $\mathrm{N} / \mathrm{A}$ & $\mathrm{N} / \mathrm{A}$ & $0.60993 \pm 0.00052$ \\
${ }^{235} \mathrm{U}$ & nubar & ${ }^{235} \mathrm{U}$ & nubar & $3.5463 \mathrm{E}-01 \pm 5.2857 \mathrm{E}-06$ \\
${ }^{238} \mathrm{U}$ & n,gamma & ${ }^{238} \mathrm{U}$ & n,gamma & $2.3026 \mathrm{E}-01 \pm 1.3177 \mathrm{E}-05$ \\
${ }^{238} \mathrm{U}$ & n,n' & ${ }^{238} \mathrm{U}$ & n,n' & $2.2708 \mathrm{E}-01 \pm 5.0836 \mathrm{E}-04$ \\
${ }^{235} \mathrm{U}$ & chi & ${ }^{235} \mathrm{U}$ & chi & $2.2628 \mathrm{E}-01 \pm 2.3219 \mathrm{E}-06$ \\
${ }^{235} \mathrm{U}$ & n,gamma & ${ }^{235} \mathrm{U}$ & n,gamma & $1.6240 \mathrm{E}-01 \pm 1.3052 \mathrm{E}-05$ \\
${ }^{56} \mathrm{Fe}$ & n,gamma & ${ }^{56} \mathrm{Fe}$ & n,gamma & $1.2125 \mathrm{E}-01 \pm 8.1510 \mathrm{E}-06$ \\
${ }^{235} \mathrm{U}$ & fission & ${ }^{235} \mathrm{U}$ & n,gamma & $1.1960 \mathrm{E}-01 \pm 8.0972 \mathrm{E}-06$ \\
${ }^{235} \mathrm{U}$ & fission & ${ }^{235} \mathrm{U}$ & fission & $1.1225 \mathrm{E}-01 \pm 1.2333 \mathrm{E}-05$ \\
${ }^{1} \mathrm{H}$ & n,gamma & ${ }^{1} \mathrm{H}$ & n,gamma & $1.0259 \mathrm{E}-01 \pm 1.6145 \mathrm{E}-05$ \\
${ }^{1} \mathrm{H}$ & elastic & ${ }^{1} \mathrm{H}$ & elastic & $8.0130 \mathrm{E}-02 \pm 8.7260 \mathrm{E}-05$ \\
${ }^{238} \mathrm{U}$ & n,n' & ${ }^{238} \mathrm{U}$ & elastic & $-7.6215 \mathrm{E}-02 \pm 4.8461 \mathrm{E}-05$ \\
${ }^{238} \mathrm{U}$ & nubar & ${ }^{238} \mathrm{U}$ & nubar & $6.0932 \mathrm{E}-02 \pm 3.6299 \mathrm{E}-07$ \\
${ }^{16} \mathrm{O}$ & elastic & ${ }^{16} \mathrm{O}$ & elastic & $4.3512 \mathrm{E}-02 \pm 6.0622 \mathrm{E}-05$ \\
${ }^{91} \mathrm{Zr}$ & n,gamma & ${ }^{91} \mathrm{Zr}$ & n,gamma & $3.9502 \mathrm{E}-02 \pm 8.5091 \mathrm{E}-07$ \\
${ }^{92} \mathrm{Zr}$ & n,gamma & ${ }^{92} \mathrm{Zr}$ & n,gamma & $3.6132 \mathrm{E}-02 \pm 7.1816 \mathrm{E}-07$ \\
\hline
\end{tabular}

Table 3. Top contributors to uncertainty in effective multiplication factor from cross section covariance data for a 2-D scoping model of the LR-0 reactor

\begin{tabular}{cccccc}
\hline Nuclide & Reaction & $\begin{array}{c}\text { Covariance } \\
\text { with nuclide }\end{array}$ & Reaction & $\begin{array}{c}\text { Uncertainty in k-effective } \\
\text { (\%delta-k/k) }\end{array}$ & $\begin{array}{c}\text { Difference } \\
\text { relative to } \\
\text { 3-D model }\end{array}$ \\
\hline${ }^{T}$ Total & N/A & N/A & N/A & $0.55775 \pm 0.00042$ & $-8.9 \%$ \\
${ }^{235} \mathrm{U}$ & nubar & ${ }^{235} \mathrm{U}$ & nubar & $3.5802 \mathrm{E}-01+/-4.9507 \mathrm{E}-06$ & $1.0 \%$ \\
${ }^{238} \mathrm{U}$ & $\mathrm{n}, \mathrm{gamma}$ & ${ }^{238} \mathrm{U}$ & n,gamma & $2.3856 \mathrm{E}-01+/-1.5208 \mathrm{E}-05$ & $3.5 \%$ \\
${ }^{235} \mathrm{U}$ & $\mathrm{n}, \mathrm{gamma}$ & ${ }^{235} \mathrm{U}$ & n,gamma & $1.7215 \mathrm{E}-01+/-1.5352 \mathrm{E}-05$ & $5.8 \%$ \\
${ }^{238} \mathrm{U}$ & $\mathrm{n}, \mathrm{n}^{\prime}$ & ${ }^{238} \mathrm{U}$ & $\mathrm{n}, \mathrm{n}^{\prime}$ & $1.6934 \mathrm{E}-01+/-4.1264 \mathrm{E}-04$ & $-29.1 \%$ \\
${ }^{235} \mathrm{U}$ & $\mathrm{chi}$ & ${ }^{235} \mathrm{U}$ & chi & $1.3774 \mathrm{E}-01+/-1.0976 \mathrm{E}-05$ & $-48.6 \%$ \\
${ }^{235} \mathrm{U}$ & fission & ${ }^{235} \mathrm{U}$ & n,gamma & $1.1807 \mathrm{E}-01+/-9.2312 \mathrm{E}-06$ & $-1.3 \%$ \\
${ }^{1} \mathrm{H}$ & $\mathrm{n}$, gamma & ${ }^{1} \mathrm{H}$ & n,gamma & $1.0868 \mathrm{E}-01+/-1.5100 \mathrm{E}-05$ & $5.8 \%$ \\
${ }^{235} \mathrm{U}$ & fission & ${ }^{235} \mathrm{U}$ & fission & $1.0279 \mathrm{E}-01+/-1.2440 \mathrm{E}-05$ & $-8.8 \%$ \\
${ }^{238} \mathrm{U}$ & $\mathrm{n}, \mathrm{n}^{\prime}$ & ${ }^{238} \mathrm{U}$ & elastic & $-7.2078 \mathrm{E}-02+/-4.9804 \mathrm{E}-05$ & $-5.6 \%$ \\
${ }^{1} \mathrm{H}$ & elastic & ${ }^{1} \mathrm{H}$ & elastic & $6.5748 \mathrm{E}-02+/-6.4647 \mathrm{E}-05$ & $-19.7 \%$ \\
\hline
\end{tabular}

In sensitivity and uncertainty analysis, the eigenvalue sensitivity coefficient is defined as:

$$
S_{k, \Sigma}=\frac{\delta k / k}{\delta \Sigma / \Sigma}
$$


Where $\Sigma$ is the system parameter (e.g. cross section) with a given uncertainty. The energy dependence of the eigenvalue sensitivity coefficients for the three-dimensional model and the two-dimensional scoping model were also considered. In general, the energy dependence and shape of the sensitivities as a function of energy were very similar for the two cases. Examples include ${ }^{235} \mathrm{U}$ nubar, which is shown in Figure 7, ${ }^{238} \mathrm{U}$ radiative capture, which is shown in Figure 8, and ${ }^{1} \mathrm{H}$ elastic neutron scattering, which is shown in Figure 9.

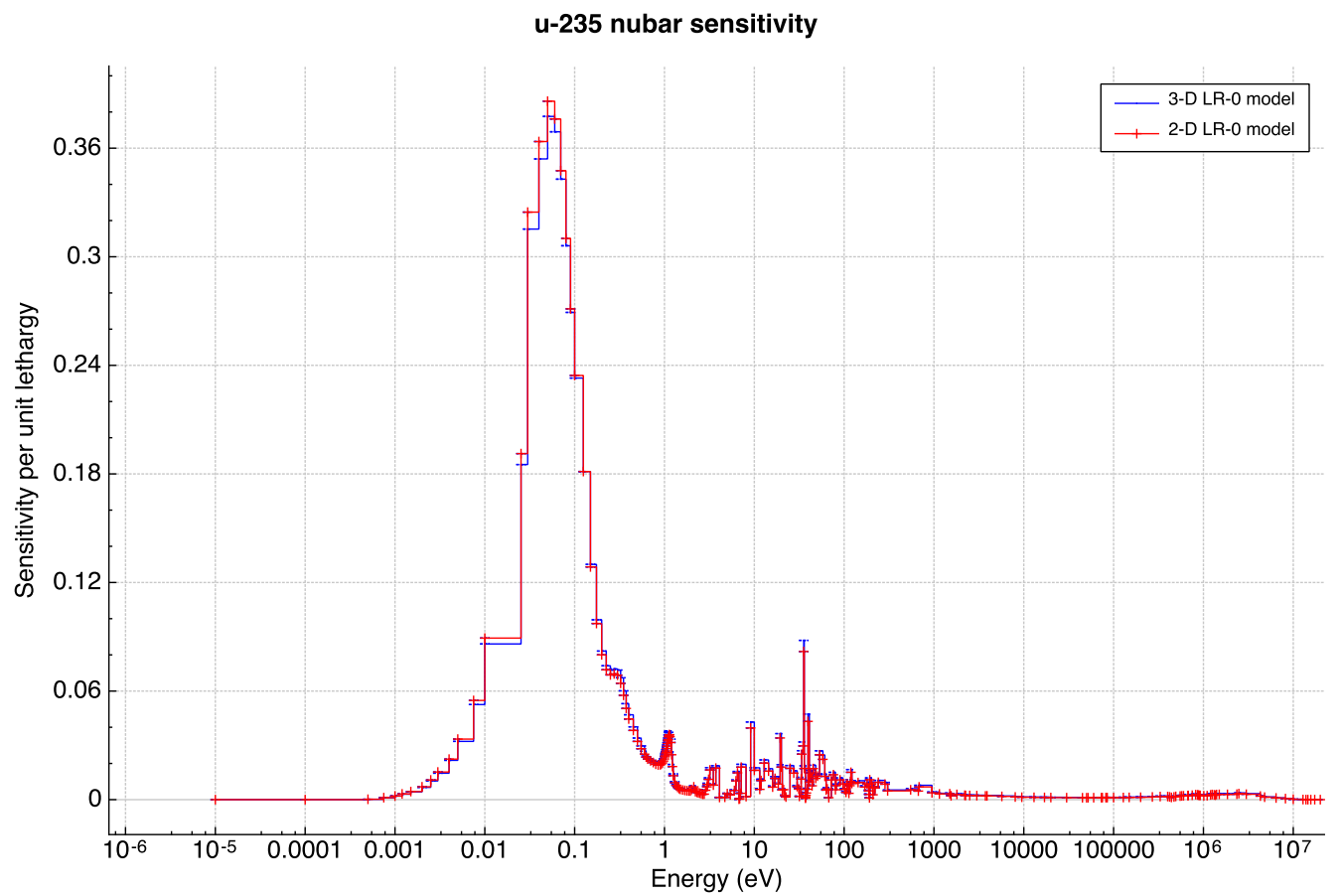

Figure $7 .{ }^{235} \mathrm{U}$ nubar sensitivity coefficients for the 3-D LR-0 model and 2-D LR-0 model.

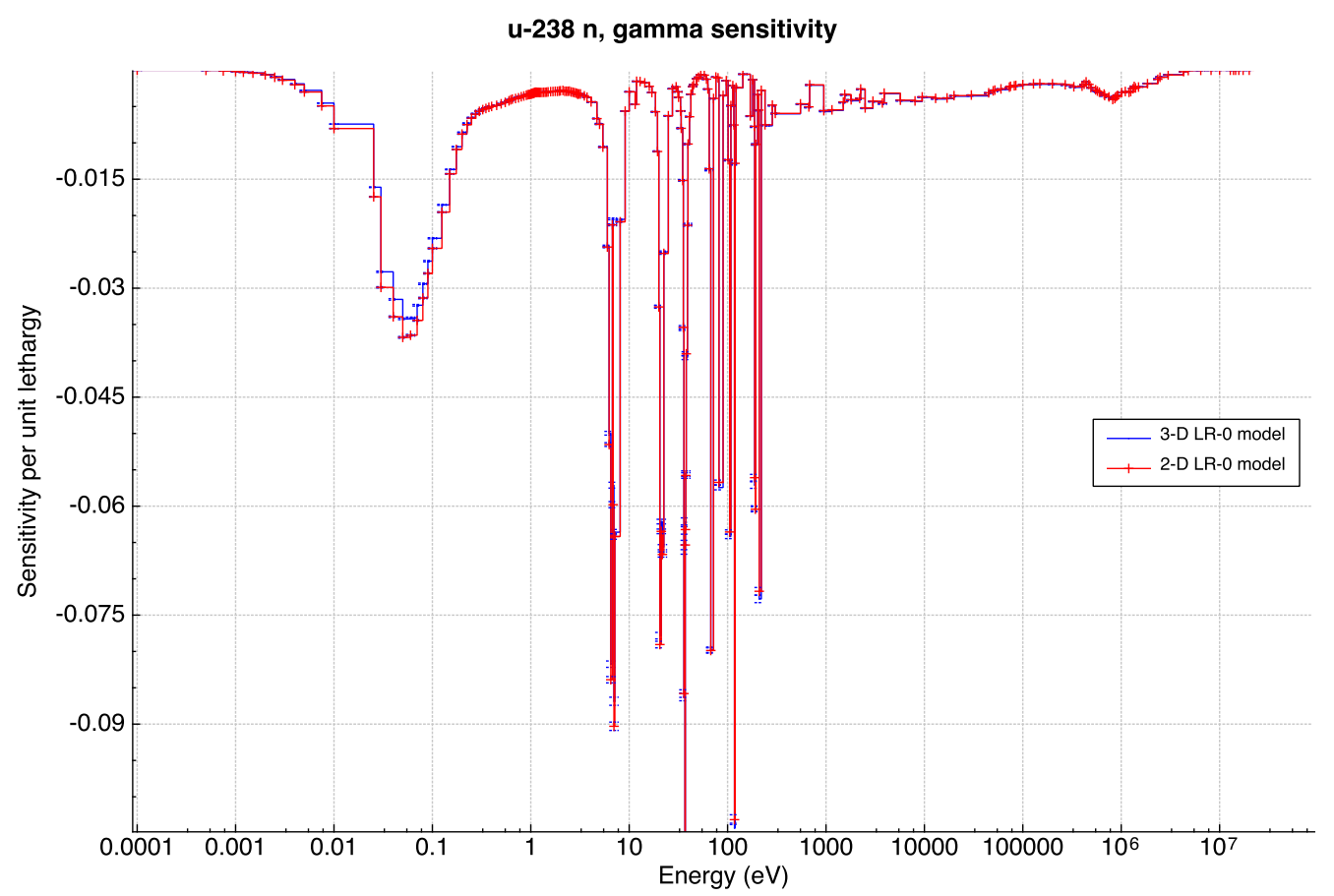

Figure 8. ${ }^{238} \mathrm{U}$ (n, gamma) sensitivity coefficients for the 3-D LR-0 model and 2-D LR-0 model. 


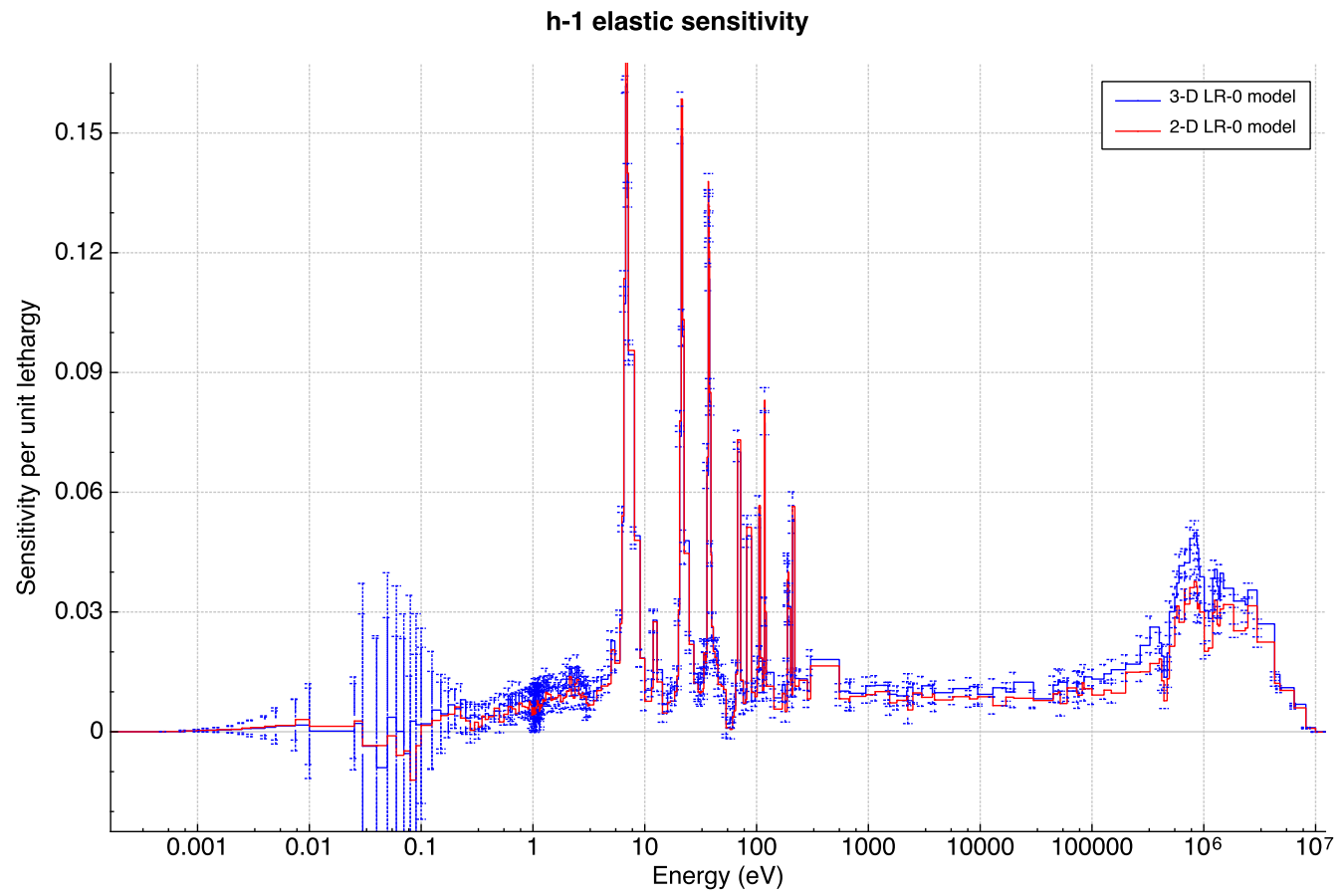

Figure 9. ${ }^{1} \mathrm{H}$ elastic scattering sensitivity coefficients for the 3-D LR-0 model and 2-D LR-0 model.

Even when there is disagreement in the magnitude of the overall sensitivity, for example with the ${ }^{235} \mathrm{U}$ fission spectrum (chi), the shape of the energy dependence of the sensitivity is very similar for the two models. This is illustrated in Figure 10. These results indicate that the two-dimensional model may be acceptable for some scoping studies of sensitivities in some LR-0 configurations.

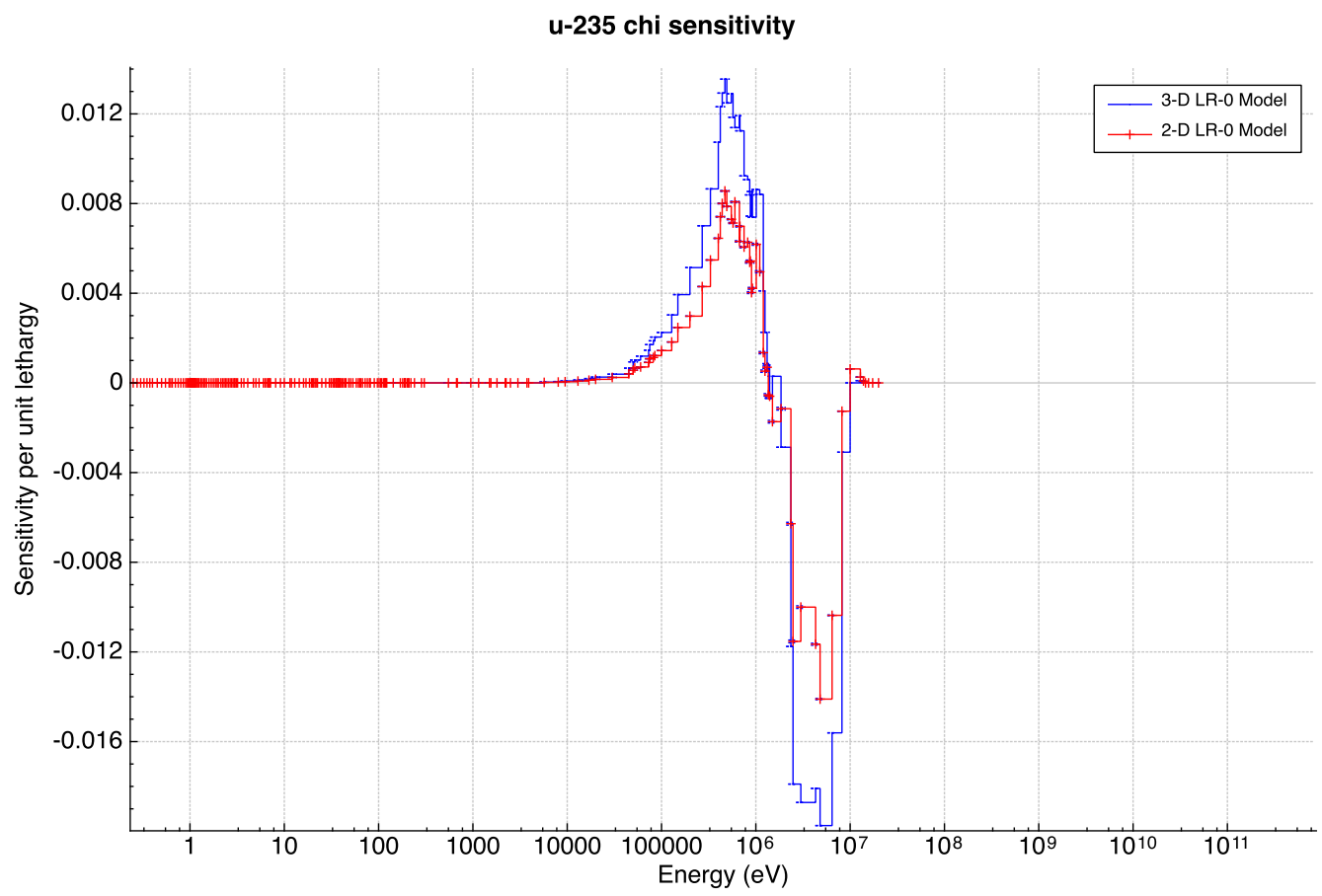

Figure 10. ${ }^{235} \mathrm{U}$ fission spectrum sensitivity coefficients for the 3-D LR-0 model and 2-D LR-0 model. 


\subsection{PRELIMINARY S/U ANALYSIS OF PLANNED MSRE FLIBE EXPERIMENTS}

RC Řež is planning critical experiments with MSRE FLiBe for the September 2016 time frame. Prior experiments focused on FLiBe salt with natural lithium [10], with a few limited experiments performed with a small amount of MSRE salt [1]. One key aspect of the planned experiments is that the MSRE salt consists of approximately $99.99+\%{ }^{7} \mathrm{Li}$ [13], which is representative of an operational MSR or FHR. However, the exact ${ }^{7} \mathrm{Li}$ enrichment of the MSRE salt is unknown. Additionally, these planned experiments will use large quantities of MSRE salt. RC Řež provided engineering drawings of the planned FLiBe insertion zone for the September 2016 experiments. An example planar view of the insertion zone is shown in Figure 11, indicating dimensions and radial features of the design.

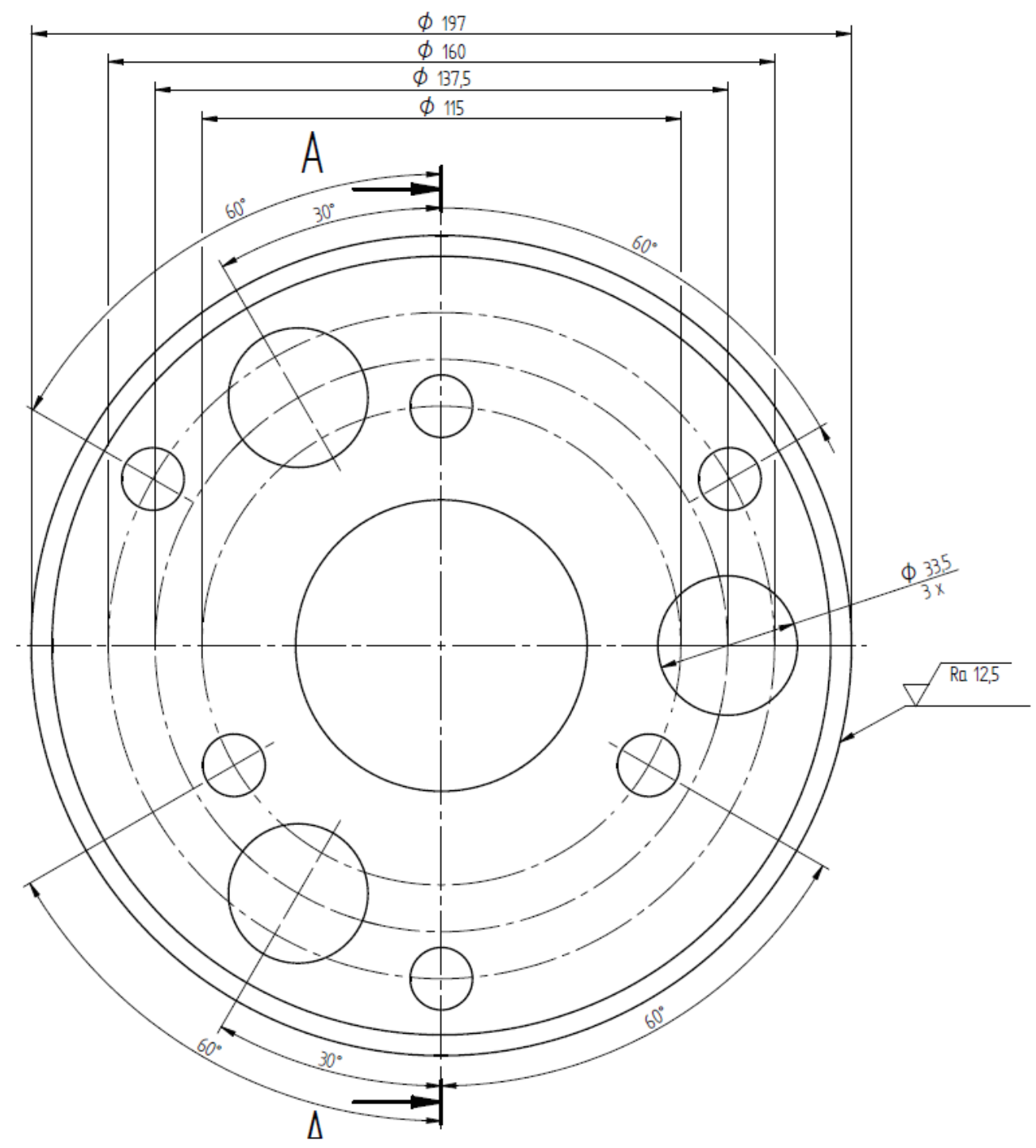

Figure 11. Planar view of the new FLiBe inserted zone for planned September 2016 experiments in the LR-0 Reactor (drawing provided by RC Řež). 
To elucidate information about the planned experiments, scoping $\mathrm{S} / \mathrm{U}$ analyses were performed using the LR-0 models with a simplified version of the new inserted zone. A planar view of the KENO-VI model with a representation of the inserted zone is shown in Figure 12.

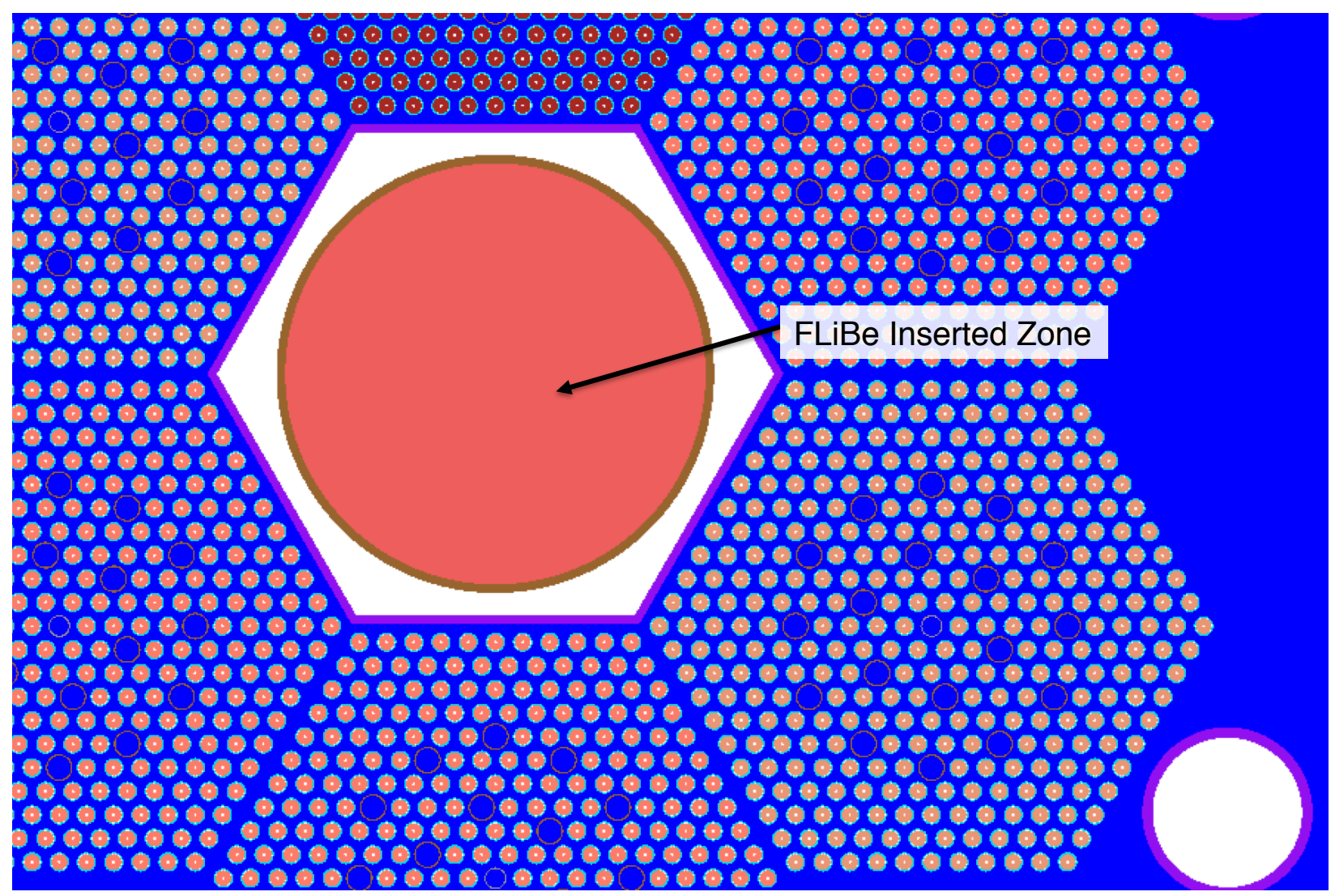

Figure 12. Simplified model of the proposed FLiBe inserted zone in the LR-0.

A comparison was conducted between the two-dimensional and three-dimensional LR-0 models for the inserted zone. The analyses indicate that the two-dimensional LR-0 model will reproduce the energy shape of the eigenvalue sensitivity for the FLiBe zone but will exaggerate the sensitivity. One example comparison of a key sensitivity is ${ }^{7} \mathrm{Li}$ (n, gamma), shown in Figure 13. This is likely due to the fact that the axially infinite FLiBe zone in the two-dimensional LR-0 model exaggerates the fraction of FLiBe relative to fuel and moderator in the three-dimensional LR-0 model. The two-dimensional model therefore exaggerates the magnitude of the importance of the FLiBe inserted zone, but it captures the relevant energy dependence. Analysis of the proposed FLiBe inserted zone is ongoing at the time of preparation of this status report. 


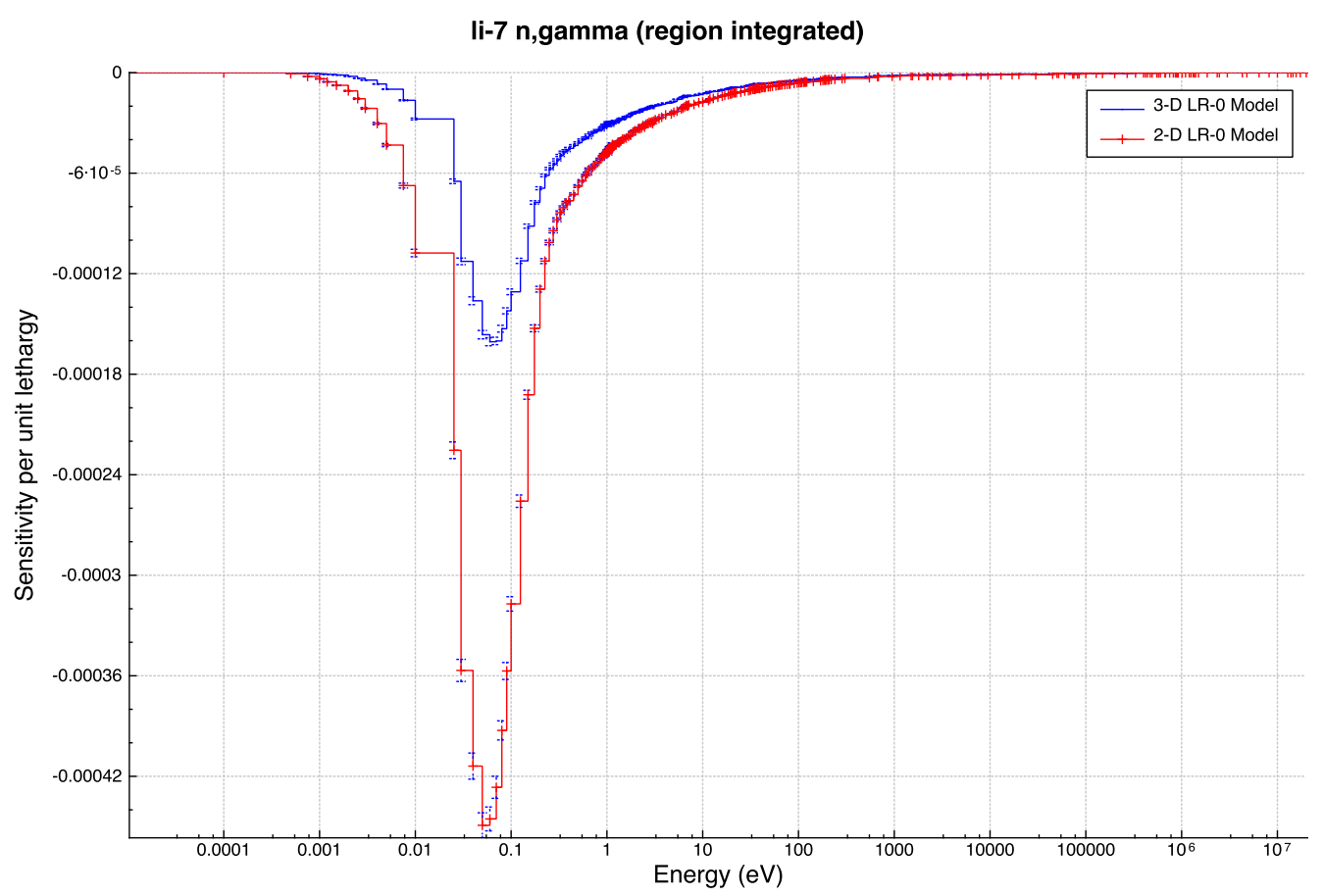

Figure 13. ${ }^{7} \mathrm{Li}$ radiative capture sensitivity coefficients for the 3-D LR-0 model and the 2-D LR-0 model with the proposed FLiBe insertion zone.

\section{SENSITIVITY AND UNCERTAINTY ANALYSIS OF A TYPICAL FLUORIDE SALT-COOLED HIGH TEMPERATURE REACTOR CONFIGURATION}

The experiments in the LR-0 reactor should effectively capture the eigenvalue sensitivity coefficients as a function of energy for FLiBe salts in relevant advanced reactor geometries. The scope of the S/U analysis in this report includes FHRs. FHRs are promising potential options that generate high-temperature heat using a low-pressure, high-power-density system (relative to high temperature gas-cooled reactors), but the technology is relatively immature. FHRs are reactor concepts with a very strong potential for inherent safety, but an FHR has never been built, and directly relevant neutronic benchmarks do not exist.

A three-dimensional assembly model from the AHTR design studies [11] was used to determine eigenvalue sensitivity coefficients. The model is a very detailed three-dimensional assembly with radially reflected boundary conditions but with axial leakage. The assembly model contains both the fuel assembly and the axial reflectors. This is a good approximation of the neutron energy spectrum in a large FHR because the radial neutron leakage in the AHTR is very low. The assembly model contains explicitly defined lattices of tri-isotropic carbon coated fuel particles. A planar slice of the model is shown in Figure 14. 


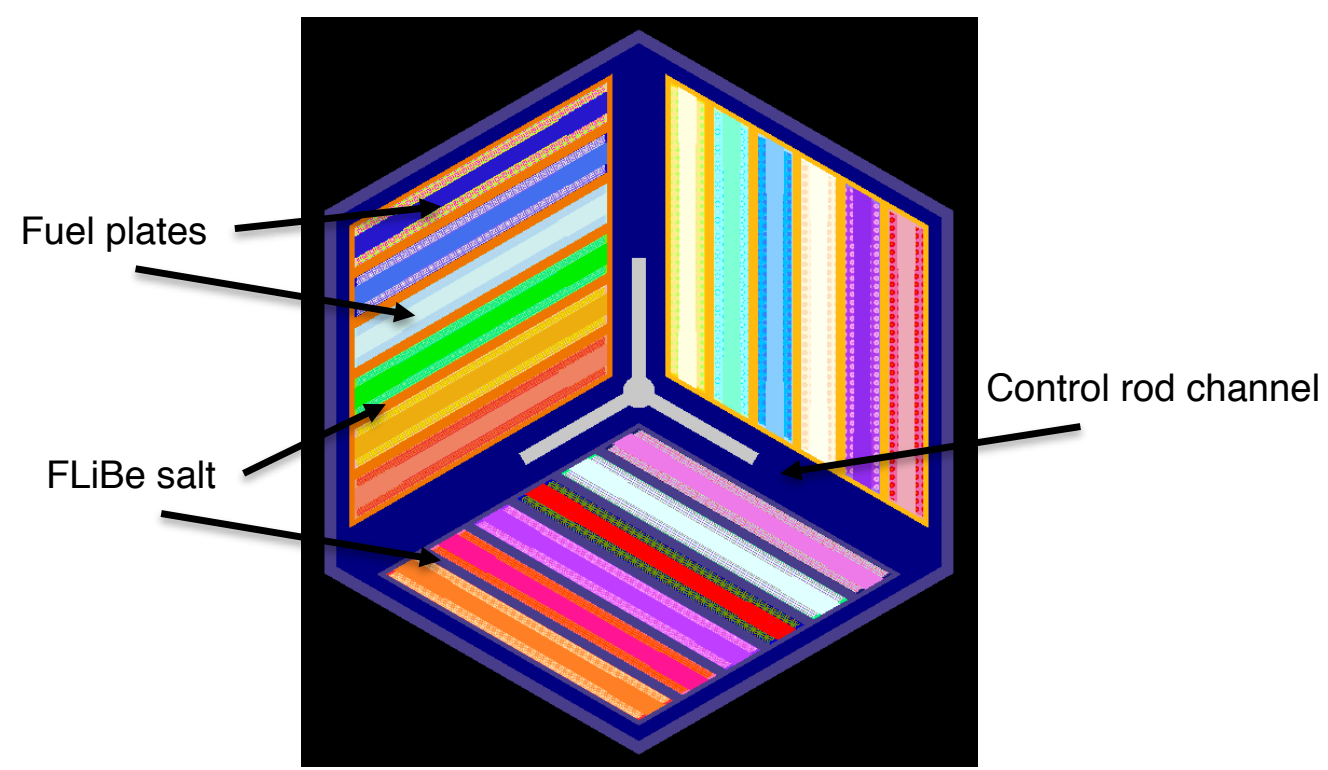

Figure 14. Planar slice of the AHTR fuel assembly model used in the $S / U$ analysis.

TSUNAMI-3D S/U analysis of the eigenvalue sensitivity coefficients was conducted with FLiBe coolant at four different ${ }^{7} \mathrm{Li}$ enrichments: $99.95 \%, 99.995 \%, 99.9995 \%$, and $100.0 \%$. The top contributors to the uncertainty in effective multiplication factor are shown in Table 4. The biggest contributors to eigenvalue uncertainty in the FLiBe coolant include ${ }^{7} \mathrm{Li}$ radiative capture and elastic scattering. To a lesser extent, ${ }^{19} \mathrm{~F}$ elastic scattering also contributes to the uncertainty.

Table 4. Top contributors to uncertainty in effective multiplication factor from cross section covariance data for the FHR assembly with FLiBe coolant at $99.995 \%{ }^{7} \mathrm{Li}$-enrichment.

\begin{tabular}{ccccc}
\hline Nuclide & Reaction & $\begin{array}{c}\text { Covariance } \\
\text { w/nuclide }\end{array}$ & Reaction & Uncertainty in $\boldsymbol{k}$-eff (\%delta-k/k) \\
\hline Total & N/A & N/A & N/A & $0.49910 \pm 0.00029$ \\
${ }^{235} \mathrm{U}$ & nubar & ${ }^{235} \mathrm{U}$ & nubar & $3.5452 \mathrm{E}-01 \pm 5.4467 \mathrm{E}-07$ \\
${ }^{235} \mathrm{U}$ & n,gamma & ${ }^{235} \mathrm{U}$ & n,gamma & $2.3637 \mathrm{E}-01 \pm 1.2881 \mathrm{E}-05$ \\
${ }^{238} \mathrm{U}$ & n,gamma ${ }^{7} \mathrm{Li}$ & ${ }^{\mathrm{u}}{ }^{238} \mathrm{U}$ & n,gamma & $1.7018 \mathrm{E}-01 \pm 1.2960 \mathrm{E}-05$ \\
${ }^{7} \mathrm{Li}$ & n,gamma & ${ }^{7} \mathrm{Li}$ & n,gamma & $1.0639 \mathrm{E}-01 \pm 3.9004 \mathrm{E}-06$ \\
${ }^{235} \mathrm{U}$ & fission & ${ }^{235} \mathrm{U}$ & n,gamma & $1.0295 \mathrm{E}-01 \pm 3.7254 \mathrm{E}-06$ \\
$\mathrm{C}$ & elastic & $\mathrm{C}$ & elastic & $8.1900 \mathrm{E}-02 \pm 2.4621 \mathrm{E}-04$ \\
${ }^{235} \mathrm{U}$ & fission & ${ }^{235} \mathrm{U}$ & fission & $6.8174 \mathrm{E}-02 \pm 2.8071 \mathrm{E}-06$ \\
${ }^{7} \mathrm{Li}$ & elastic & ${ }^{7} \mathrm{Li}$ & elastic & $3.0159 \mathrm{E}-02 \pm 3.6913 \mathrm{E}-05$ \\
${ }^{238} \mathrm{U}$ & elastic & ${ }^{238} \mathrm{U}$ & elastic & $2.6592 \mathrm{E}-02 \pm 6.7705 \mathrm{E}-06$ \\
${ }^{28} \mathrm{Si}$ & n,gamma & ${ }^{28} \mathrm{Si}$ & n,gamma & $2.5741 \mathrm{E}-02 \pm 8.7678 \mathrm{E}-08$ \\
${ }^{19} \mathrm{~F}$ & elastic & ${ }^{19} \mathrm{~F}$ & elastic & $2.1998 \mathrm{E}-02 \pm 7.5823 \mathrm{E}-05$ \\
${ }^{19} \mathrm{~F}$ & n,alpha & ${ }^{19} \mathrm{~F}$ & n,alpha & $2.0638 \mathrm{E}-02 \pm 1.1924 \mathrm{E}-06$ \\
${ }^{9} \mathrm{Be}$ & n,2n & ${ }^{9} \mathrm{Be}$ & n,2n & $2.0026 \mathrm{E}-02 \pm 1.3830 \mathrm{E}-06$ \\
${ }^{235} \mathrm{U}$ & n,gamma & ${ }^{23}$ & n,gamma & $1.9069 \mathrm{E}-02 \pm 6.6430 \mathrm{E}-08$ \\
& chi & ${ }^{235} \mathrm{U}$ & chi & $1.6236 \mathrm{E}-02 \pm 1.2759 \mathrm{E}-06$ \\
\hline
\end{tabular}


The contribution of the ${ }^{7} \mathrm{Li}$ radiative capture cross section to the overall uncertainty varies as a function of ${ }^{7} \mathrm{Li}$ enrichment, as shown in Table 5. The energy dependence of this sensitivity coefficient is shown in Figure 15.

$\begin{gathered}\text { Table 5. Contribution of }{ }^{7} \mathbf{L i} \text { radiative capture to overall effective multiplication } \\
\text { factor uncertainty as a function of }{ }^{7} \text { Li-enrichment in FLiBe coolant. }\end{gathered}$
\begin{tabular}{cc}
${ }^{7}$ Li-enrichment & Uncertainty in k-effective (\%delta-k/k) \\
99.95 & $9.2460 \mathrm{E}-02 \pm 1.8125 \mathrm{E}-06$ \\
99.995 & $1.0639 \mathrm{E}-01 \pm 3.9004 \mathrm{E}-06$ \\
99.9995 & $1.1668 \mathrm{E}-01 \pm 1.3741 \mathrm{E}-05$ \\
100.0 & $1.1617 \mathrm{E}-01 \pm 1.5561 \mathrm{E}-05$ \\
\hline
\end{tabular}

li-7 n,gamma (region integrated)

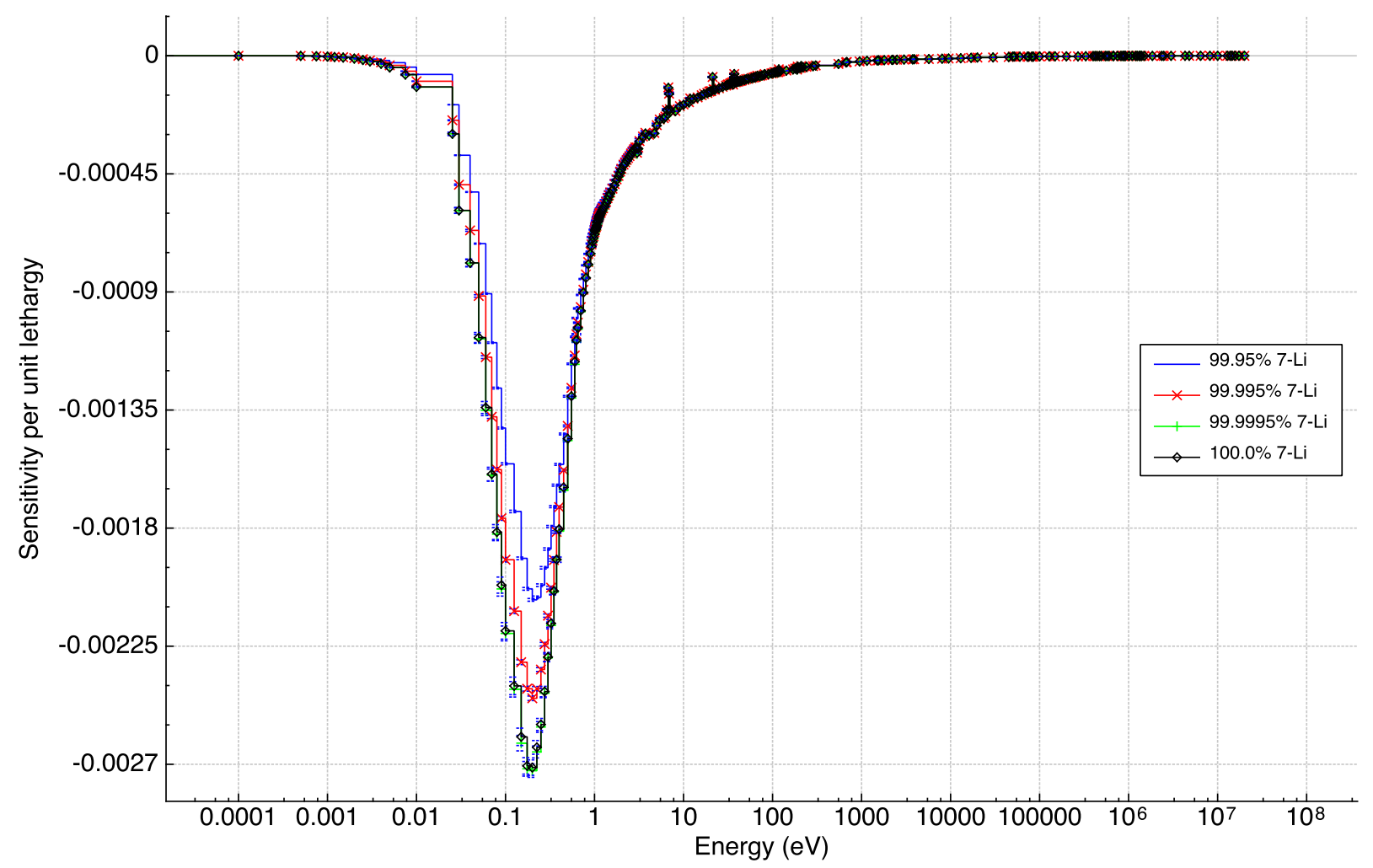

Figure $15 .{ }^{7}$ Li radiative capture sensitivity coefficients for the 3-D FHR assembly model.

Another important reaction in FLiBe is ${ }^{6} \mathrm{Li}(\mathrm{n}, \mathrm{t})$. This reaction is responsible for the generation of tritium in a FLiBe salt cooled or fueled reactor. Therefore, it is vital that the uncertainty in this reaction is understood. The eigenvalue sensitivity coefficients for ${ }^{6} \mathrm{Li}(\mathrm{n}, \mathrm{t})$ are shown in Table 6 as a function of ${ }^{7} \mathrm{Li}$-enrichment. As expected, the results show that the sensitivity coefficients are greatest when the ${ }^{7} \mathrm{Li}$-enrichment is least. The results also show significant sensitivity in a ratio with ${ }^{235} \mathrm{U}$ fission. This is significant, because it is indicative of the void coefficient, which can be positive at lower ${ }^{7} \mathrm{Li}$-enrichment and negative at higher ${ }^{7} \mathrm{Li}$-enrichment. The energy dependence of this sensitivity is shown in Figure 16. 
Table 6. Contribution of ${ }^{6} \mathrm{Li}(\mathrm{n}, \mathrm{t})$ to overall effective multiplication factor uncertainty as a function of ${ }^{7} \mathrm{Li}$-enrichment in FLiBe coolant.

\begin{tabular}{cccccc}
\hline $\begin{array}{c}{ }^{7} \mathbf{L i}- \\
\text { enrichment }\end{array}$ & Nuclide & Reaction & $\begin{array}{c}\text { Covariance } \\
\text { w/nuclide }\end{array}$ & Reaction & $\begin{array}{c}\text { Uncertainty in k-effective } \\
\text { (\%delta-k/k) }\end{array}$ \\
\hline 99.95 & ${ }^{6} \mathrm{Li}$ & $\mathrm{n}, \mathrm{t}$ & ${ }^{6} \mathrm{Li}$ & $\mathrm{n}, \mathrm{t}$ & $9.9515 \mathrm{E}-03 \pm 2.1280 \mathrm{E}-08$ \\
99.95 & ${ }^{6} \mathrm{Li}$ & $\mathrm{n}, \mathrm{t}$ & ${ }^{235} \mathrm{U}$ & fission & $-4.2421 \mathrm{E}-03 \pm 3.1259 \mathrm{E}-09$ \\
99.995 & ${ }^{6} \mathrm{Li}$ & $\mathrm{n}, \mathrm{t}$ & ${ }^{235} \mathrm{U}$ & fission & $-1.3052 \mathrm{E}-03 \pm 4.2600 \mathrm{E}-10$ \\
99.995 & ${ }^{6} \mathrm{Li}$ & $\mathrm{n}, \mathrm{t}$ & ${ }^{6} \mathrm{Li}$ & $\mathrm{n}, \mathrm{t}$ & $1.1454 \mathrm{E}-03 \pm 4.5815 \mathrm{E}-10$ \\
99.9995 & ${ }^{6} \mathrm{Li}$ & $\mathrm{n}, \mathrm{t}$ & ${ }^{235} \mathrm{U}$ & fission & $-4.2438 \mathrm{E}-04 \pm 1.0392 \mathrm{E}-10$ \\
99.9995 & ${ }^{6} \mathrm{Li}$ & $\mathrm{n}, \mathrm{t}$ & ${ }^{6} \mathrm{Li}$ & $\mathrm{n}, \mathrm{t}$ & $1.2568 \mathrm{E}-04 \pm 1.6155 \mathrm{E}-11$ \\
100.0 & ${ }^{6} \mathrm{Li}$ & $\mathrm{n}, \mathrm{t}$ & ${ }^{235} \mathrm{U}$ & fission & N/A \\
100.0 & ${ }^{6} \mathrm{Li}$ & $\mathrm{n}, \mathrm{t}$ & ${ }^{6} \mathrm{Li}$ & $\mathrm{n}, \mathrm{t}$ & N/A \\
\hline
\end{tabular}

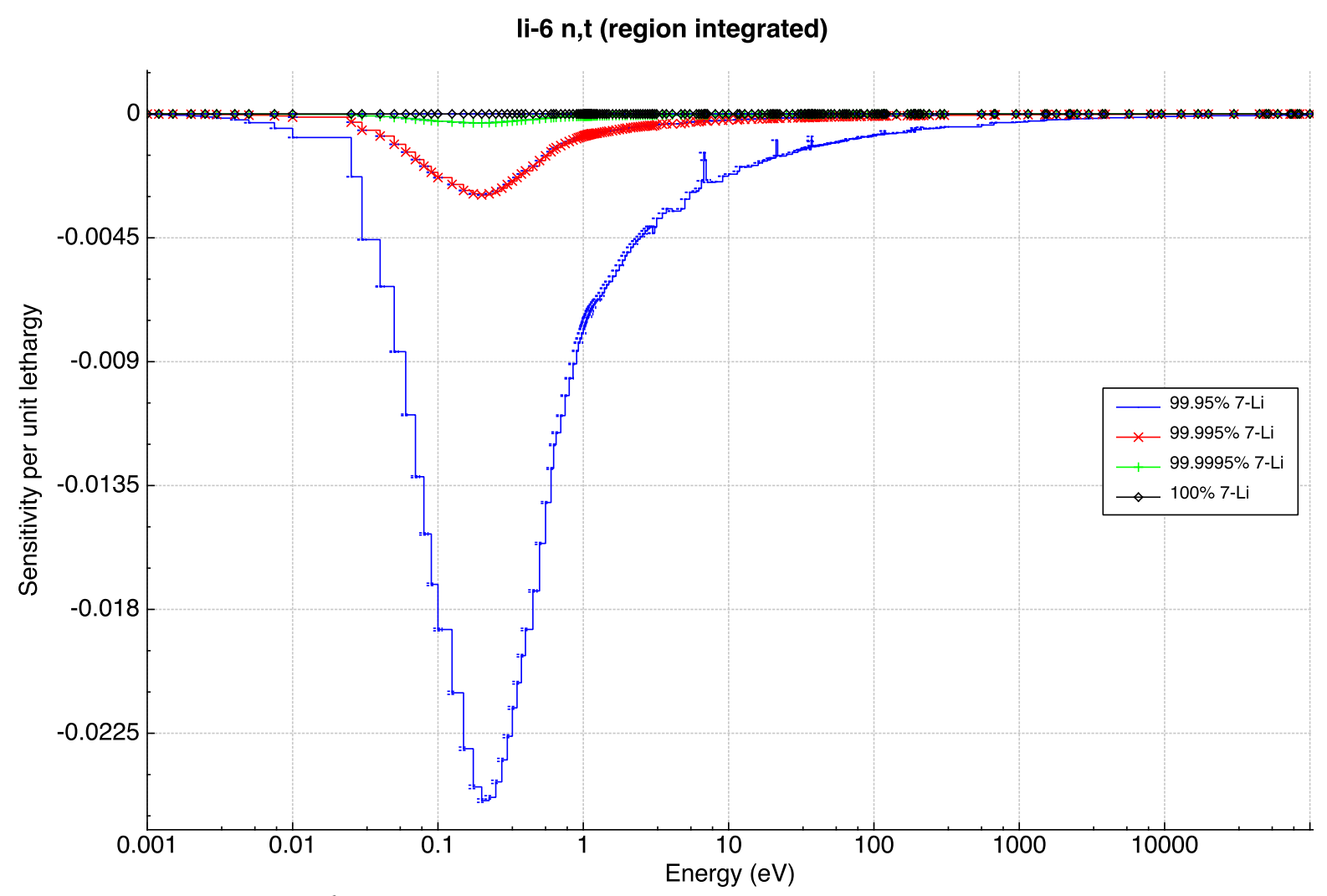

Figure 16. ${ }^{6} \mathrm{Li}(\mathrm{n}, \mathrm{t})$ sensitivity coefficients for the 3-D FHR assembly model. 


\section{SENSITIVITY AND UNCERTAINTY ANALYSIS OF REPRESENTATIVE LIQUID- FUELED MOLTEN SALT REACTOR CONFIGURATIONS}

The FLiBe salt experiments in the LR-0 reactor should also effectively capture the eigenvalue sensitivity coefficients as a function of energy for liquid-fueled thermal-spectrum MSRs using FLiBe as the carrier salt for the fuel. Liquid-fueled MSRs offer several unique characteristics that most solid-fueled systems cannot achieve, including online refueling and removal of fission products, that could improve resource utilization or decrease potential safety concerns. MSRs also come with several potential technical challenges, including corrosion concerns and tritium containment, and despite having the MSRE as an early engineering-scale demonstration reactor [12], MSRs remain relatively immature as a reactor technology. Significant public and private interest has surfaced recently in liquid-fueled MSR concepts due to their potential benefits and wide range of possible design space and operational modes. These recent efforts, many of which are privately funded design and technology development efforts at startup companies, cover a range of MSR designs, including options in the fuel (uranium, thorium, or recycled spent nuclear fuel from existing light water reactors), neutron energy spectrum (thermal, intermediate, fast, or mixed spectrum), and fuel cycles approaches (open fuel cycle with once-through or limited recycle, or a closed fuel cycle with continuous recycle). In particular, thorium-fueled MSRs are of potential interest in the thermal neutron energy spectrum [14], as well as the intermediate or fast neutron energy spectrum [15] depending upon specific design choices and missions.

MSR application models used to date for this S/U analysis effort were built using an existing twodimensional unit cell model of a single-zone one-fluid MSR based on the MSBR. This model was adapted to analyze two representative MSR systems of interest: (1) a thermal-spectrum low-enriched uraniumfueled MSR operating in a once-through fuel cycle, and (2) a thermal-spectrum thorium-fueled MSR with continuous recycle of ${ }^{233} \mathrm{U}$ produced in the system. The simple two-dimensional models of a salt flow channel in a graphite block use radial and axial reflective boundary conditions and miss possible benefits of going to a two-zone system with different neutron energy spectra in the zones to enhance breeding or burning. However, this two-dimensional approach provides quick scoping calculations and should be a reasonable approximation of the neutron energy spectrum in a large MSR using a similar fuel and actinide management strategy. The overall geometry for an example unit cell from these application models, shown below in Figure 17, remains the same as the base model, though values and material compositions may vary for specific parameters and regions.

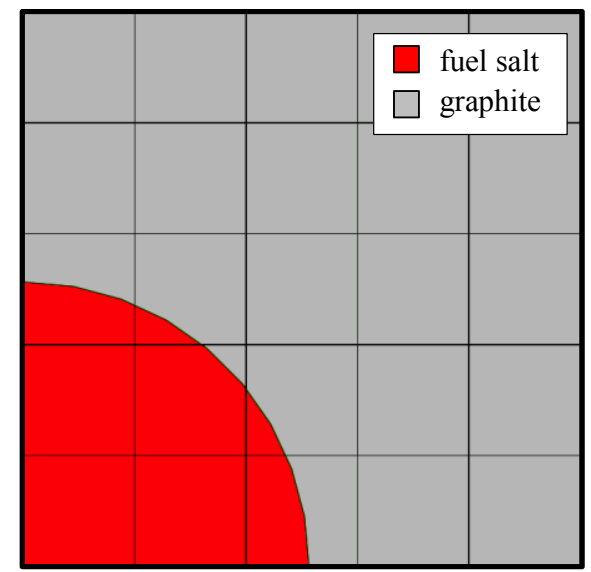

Figure 17. Unit cell geometry for an MSR application model, reproduced from Reference 15. 
For the Th/ ${ }^{233} \mathrm{U}$ MSR model, TSUNAMI-3D S/U analysis of the eigenvalue sensitivity coefficients was conducted to identify the top contributors to the uncertainty in effective multiplication factor, which are shown in Table 7. The biggest contributors to eigenvalue uncertainty in the fuel salt include ${ }^{233} \mathrm{U}$ nubar, ${ }^{232} \mathrm{Th}$ radiative capture, ${ }^{7} \mathrm{Li}$ radiative capture, and $\mathrm{C}$ (natural carbon) radiative capture and elastic scattering. Smaller contributions also come from ${ }^{19} \mathrm{~F}$ radiative capture. These contributors highlight the fact that liquid-fueled systems using $\mathrm{Th} /{ }^{233} \mathrm{U}$ fuel will have some significant contributors that will not be present in LR-0 (e.g., ${ }^{233} \mathrm{U}$ and ${ }^{232} \mathrm{Th}$ ) but will also have significant contributors (e.g., ${ }^{7} \mathrm{Li}$ and ${ }^{19} \mathrm{~F}$ ) for which LR-0 experiments may help provide experimental data. Figure 18 shows the energy dependence of some of the top contributors in the $\mathrm{Th} /{ }^{233} \mathrm{U}$ MSR model, with peak sensitivities occurring around a neutron energy level of $0.2 \mathrm{eV}$.

Table 7. Top contributors to uncertainty in effective multiplication factor from cross section covariance data for the Th $/{ }^{233} \mathrm{U}$ MSR unit cell with $100 \%{ }^{7} \mathrm{Li}$-enrichment in FLiBe.

\begin{tabular}{ccccc}
\hline Nuclide & Reaction & $\begin{array}{c}\text { Covariance } \\
\text { w/nuclide }\end{array}$ & Reaction & Uncertainty in $\boldsymbol{k}_{\text {eff }}$ (\%delta-k/k) \\
\hline${ }^{T}$ Total & N/A & N/A & N/A & $0.7628 \pm 0.0014$ \\
${ }^{233} \mathrm{U}$ & nubar & ${ }^{233} \mathrm{U}$ & nubar & $4.8371 \mathrm{E}-01 \pm 5.1016 \mathrm{E}-06$ \\
${ }^{232} \mathrm{Th}$ & n,gamma & ${ }^{232} \mathrm{Th}$ & n,gamma & $4.7515 \mathrm{E}-01 \pm 9.6106 \mathrm{E}-05$ \\
${ }^{7} \mathrm{Li}$ & n,gamma & ${ }^{7} \mathrm{Li}$ & n,gamma & $2.0384 \mathrm{E}-01 \pm 1.6949 \mathrm{E}-05$ \\
${ }^{233} \mathrm{U}$ & fission & ${ }^{233} \mathrm{U}$ & fission & $2.0035 \mathrm{E}-01 \pm 1.6820 \mathrm{E}-05$ \\
$\mathrm{C}$ & n,gamma & $\mathrm{C}$ & n,gamma & $1.5826 \mathrm{E}-01 \pm 1.0997 \mathrm{E}-05$ \\
${ }^{233} \mathrm{U}$ & n,gamma & ${ }^{233} \mathrm{U}$ & n,gamma & $1.0947 \mathrm{E}-01 \pm 5.0975 \mathrm{E}-06$ \\
${ }^{\mathrm{C}}$ & elastic & $\mathrm{C}$ & elastic & $3.6879 \mathrm{E}-02 \pm 1.4531 \mathrm{E}-03$ \\
${ }^{19} \mathrm{~F}$ & n,gamma & ${ }^{19} \mathrm{~F}$ & n,gamma & $3.0069 \mathrm{E}-02 \pm 3.6674 \mathrm{E}-07$ \\
${ }^{233} \mathrm{U}$ & fission & ${ }^{233} \mathrm{U}$ & n,gamma & $2.1752 \mathrm{E}-02 \pm 1.4059 \mathrm{E}-06$ \\
${ }^{233} \mathrm{U}$ & chi & ${ }^{233} \mathrm{U}$ & chi & $1.8172 \mathrm{E}-02 \pm 1.5442 \mathrm{E}-06$ \\
${ }^{19} \mathrm{~F}$ & n,alpha & ${ }^{19} \mathrm{~F}$ & n,alpha & $1.5054 \mathrm{E}-02 \pm 6.2545 \mathrm{E}-07$ \\
${ }^{232} \mathrm{Th}$ & elastic & ${ }^{232} \mathrm{Th}$ & n,gamma & $-1.1262 \mathrm{E}-02 \pm 2.0932 \mathrm{E}-05$ \\
$\mathrm{C}$ & n,n' & $\mathrm{C}$ & n,n' & $1.1053 \mathrm{E}-02 \pm 1.7937 \mathrm{E}-05$ \\
$\mathrm{C}$ & n,alpha & $\mathrm{C}$ & n,alpha & $9.6364 \mathrm{E}-03 \pm 5.3393 \mathrm{E}-07$ \\
$\mathrm{C}$ & elastic & $\mathrm{C}$ & n,n' & $-7.4464 \mathrm{E}-03 \pm 1.0438 \mathrm{E}-05$ \\
\hline
\end{tabular}


Th/U-233 MSR Sensitivities (region integrated)

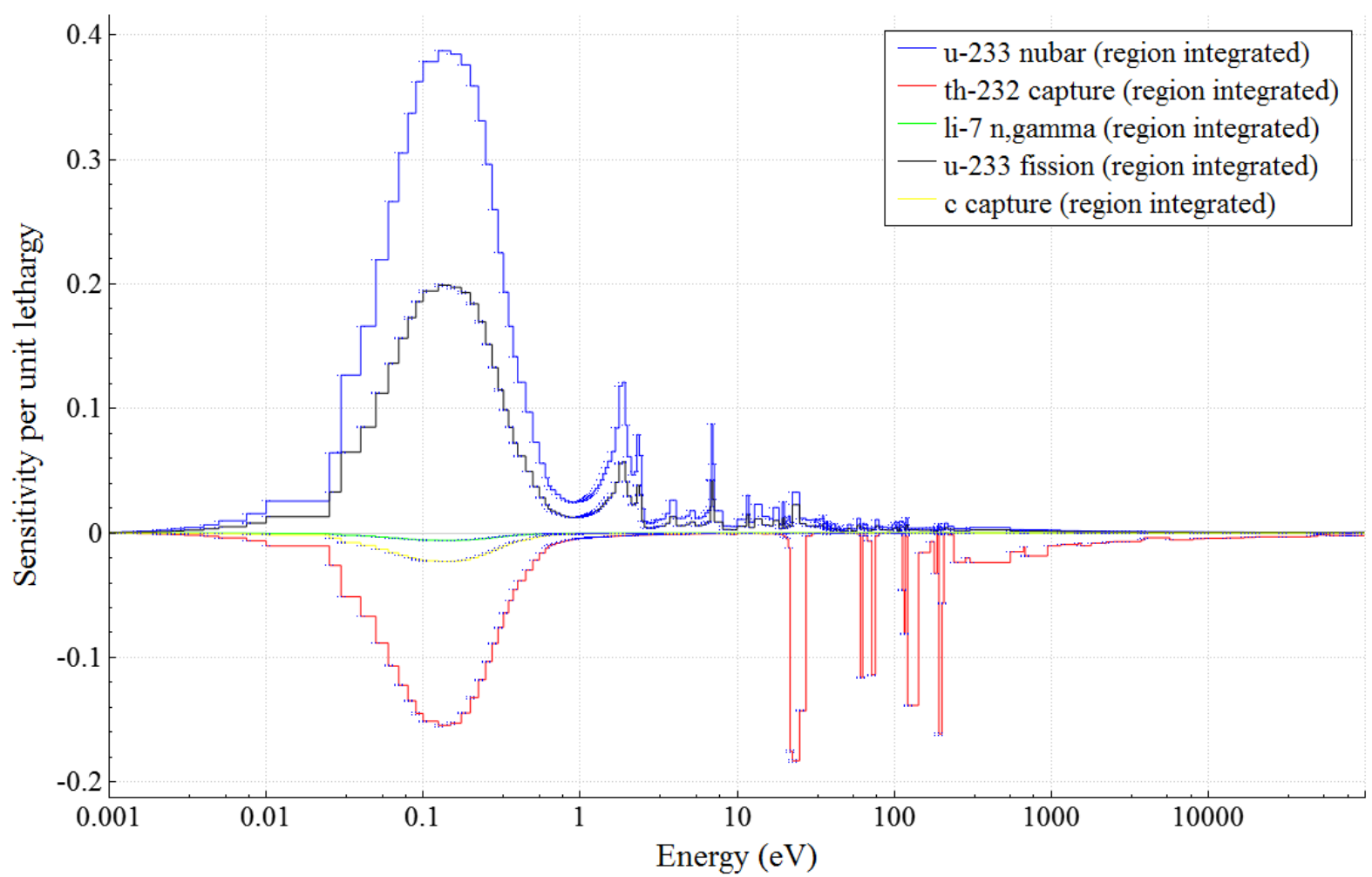

Figure 18. Sensitivity coefficients for top contributors in $T h /{ }^{233} U$ MSR model.

The analysis of the $\mathrm{Th} /{ }^{233} \mathrm{U}$ MSR application model above was only performed using a ${ }^{7} \mathrm{Li}$ enrichment of $100 \%$ in the FLiBe carrier salt. Ongoing work during this effort may expand the Th/ ${ }^{233} \mathrm{U}$ MSR analysis to other ${ }^{7} \mathrm{Li}$ enrichments, though overall trends shown for ${ }^{7} \mathrm{Li}$ enrichment will likely be consistent with analyses for LEU MSRs and FHRs.

Results from TSUNAMI-3D S/U analysis for the LEU MSR application model will be available in the near future at four different ${ }^{7} \mathrm{Li}$ enrichments in the FLiBe carrier salt: $99.95 \%, 99.995 \%, 99.9995 \%$, and $100.0 \%$. The final December 2016 report will document these results, including identifying the top contributors to the uncertainty in effective multiplication factor for the LEU MSR application model, as well as showing the impact of ${ }^{7} \mathrm{Li}$ enrichment on parameters of interest. 


\section{SUMMARY}

This status report milestone is an initial version of an expanded project report that will be issued in December 2016. In FY2016, ORNL accomplished the following in support of the collaboration:

- In May 2016, a delegation from the United States visited the Czech Republic and conducted observations of experimental operations at the LR-0 reactor and also engaged in collaborative discussions on the enhancements to experiments in LR-0 that $\mathrm{S} / \mathrm{U}$ analysis can provide.

- Simplified two-dimensional and detailed three-dimensional models of the LR-0 reactor were developed using the SCALE code system. The detailed models show excellent agreement with draft benchmark evaluations intended for the International Handbook of Evaluated Reactor Physics Benchmark Experiments.

- Scoping S/U analyses were performed for several example configurations of the LR-0. These S/U analyses show similar sensitivities in LR-0 relative to other light water reactors, with approximately $0.61 \%$ delta- $\mathrm{k} / \mathrm{k}$ uncertainty in the neutron multiplication factor.

- Key sensitivities for a baseline configuration (no insertions) of the LR-0 include the average number of neutrons released per ${ }^{235} \mathrm{U}$ fission and neutron scattering in ${ }^{238} \mathrm{U}$.

- Application models were adapted for S/U analysis of FHR and MSR concepts. These models are representative of the AHTR and MSBR designs.

- The models were used to perform initial scoping S/U analyses for FHR and MSR concepts. The objective of the LR-0 experiments should be to generate experimental configurations that reproduce these sensitivities. Key sensitivities in FLiBe-cooled configurations include radiative capture in ${ }^{7} \mathrm{Li}$ and neutron scattering in ${ }^{7} \mathrm{Li}$. Another key sensitivity is neutron capture in ${ }^{6} \mathrm{Li}$. Parametric studies were conducted of the sensitivity of the multiplication factor to enrichment in ${ }^{7} \mathrm{Li}$. 


\section{REFERENCES}

1. J. Uhlir, "Czech Experimental Program in Molten Salt Reactor Physics," MSR Workshop, Oak Ridge, Tennessee, Oct. 15-16 (2015). https://public.ornl.gov/conferences/MSR2015/pdf/09Uhlir\%20- \%20Czech\%20exp\%20program\%20in\%20MSR\%20 physics.pdf. Accessed July 27, 2016.

2. United States Department of Energy and Czech Republic Ministry of Industry and Trade, "Agreement for Cooperation in Civilian Nuclear Energy Research and Development" (Mar. 26, 2014). http://www.energy.gov/sites/prod/files/2014/04/f14/U.S.-

Czech\%20Civilian\%20Nuclear\%20Energy\%20Research\%20and\%20Development\%20Cooperation \%20Agreement\%20-\%20English.pdf. Accessed July 27, 2016.

3. M. S. Greenwood, N. R. Brown, B. R. Betzler, and G. T. Mays, "Summary of the Workshop on Molten Salt Reactor Technologies Commemorating the 50th Anniversary of the Startup of the Molten Salt Reactor Experiment," ICAPP 2016: Nuclear Innovation: Inventing the Future of Existing and New Nuclear Power; April 17-20; San Francisco, CA, USA (2016).

4. O. Sochor and R. Stary, "The experimental reactor LR-0 after five years' operation." Nukleon (1988): 5-10.

5. M. Koštál, M. Švadlenková, and J. Milčák, “Absolute determination of power density in the VVER-1000 mock-up on the LR-0 research reactor." Applied Radiation and Isotopes 78 (2013): $38-45$.

6. C. M. Perfetti, B. T. Rearden, and W. R. Martin, "SCALE Continuous-Energy Eigenvalue Sensitivity Coefficient Calculations." Nuclear Science and Engineering 182, No. 3 (2016): 332353.

7. B. T. Rearden and M. A. Jessee, Eds., SCALE Code System, ORNL/TM-2005/39, Version 6.2, Oak Ridge National Laboratory, Oak Ridge, TN (2016).Available from Radiation Safety Information Computational Center as CCC-834.

8. M. Košt'ál et al., VVER-1000 Physics Experiments Hexagonal Lattices (1.275 cm Pitch) of Low Enriched U(3.3 wt.\% U235)O2 Fuel Assemblies in Light Water with Graphite and Fluoride Salt Insertions in Central Assembly, DRAFT Evaluation for the International Handbook of Evaluated Reactor Physics Benchmark Experiments (March 2016).

9. M. Košt’ál et al., "Comparison of fast neutron spectra in graphite and FLINA salt inserted in welldefined core assembled in LR-0 reactor.” Annals of Nuclear Energy 83 (2015): 216-225.

10. E. Losa et al., "Effect of inserted fluoride salts on criticality in the LR-0 reactor." Annals of Nuclear Energy 81 (2015): 18-25.

11. V. K. Varma, D. E. Holcomb, F. J. Peretz, E. C. Bradley, D. Ilas, A. L. Qualls, and N. M. Zaharia, AHTR mechanical, structural, and neutronic preconceptual design. ORNL/TM-2012/320. Oak Ridge National Laboratory (ORNL), Oak Ridge, TN, United States (2012). 
12. J. C. Gehin, and J. J. Powers, "Liquid fuel molten salt reactors for thorium utilization." Nuclear Technology 194, no. 2 (2016).

13. R. C. Robertson, “Operations Report; Part I, Description of Reactor Design.” ORNL-TM-728 (January 1965).

14. J. J. Powers, J. C. Gehin, A. Worrall, T. J. Harrison, and E. E. Sunny, "An Inventory Analysis of Thermal-spectrum Thorium-fueled Molten Salt Reactor Concepts." Proceedings of PHYSOR 2014, Kyoto, Japan, September 28-October 3, 2014.

15. N. R. Brown, J. J. Powers, B. Feng, F. Heidet, N. E. Stauff, G. Zhang, M. Todosow, A. Worrall, J. C. Gehin, T. K. Kim, and T. A. Taiwo, "Sustainable thorium nuclear fuel cycles: A comparison of intermediate and fast neutron spectrum systems." Nuclear Engineering and Design 289 (2015): $252-265$. 